\title{
EXPERIMENTAL AND NUMERICAL STUDIES ON WATER FLOW THROUGH RECTANGULAR CROSS-SECTIONAL AREA S-SHAPED DIFFUSERS
}

\author{
K. A. Ibrahim ${ }^{1}$, W. A. El-Askary ${ }^{1}$, I. M. Sakr ${ }^{1}$ and Hamdy A. Omara ${ }^{2}$ \\ ${ }^{1}$ Mechanical Power Engineering Department, Faculty of Engineering, \\ Menoufiya University, Shebin El-Kom, EGYPT \\ ${ }^{2}$ Higher Institute of Engineering \&Technology, Arish, North Sinai
}

\begin{abstract}
The paper presents comprehensive experimental and numerical studies on water flow through rectangular S-shaped diffusers. The experimental setup was designed and constructed to perform the measurements which have been carried out on twelve models of S-shaped diffusers. The measurements of pressure distributions along the outer and inner walls of the S-shaped diffuser were performed for different parameters including area ratios, curvature ratios, inflow Reynolds numbers, turning angles $\left(45^{\circ} / 45^{\circ}\right.$, $\left.60^{\circ} / 60^{\circ}, 90^{\circ} / 90^{\circ}\right)$, and flow paths $\left(45^{\circ} / 45^{\circ}, 60^{\circ} / 30^{\circ}, 30^{\circ} / 60^{\circ}\right)$. The energy-loss coefficients for each model are based on detailed measurements of the wall pressure distributions along walls of the S-shaped -diffuser models including long upstream and downstream tangents. The energy-loss coefficient data were plotted as a function of Reynolds number for the tested models at different geometrical parameters. The experimental data for different S-diffuser configurations have been used for assessing credibility of the numerical code using different turbulence models. High performances of computations with turbulence closure provided by the standard k- $\varepsilon$ model have been carried out for prediction of the performance of S-diffusers at different inflow and geometrical conditions. The results showed that the diffuser energy-loss coefficient is strongly affected by the geometrical parameters of S-shaped diffuser and inflow Reynolds number. Increasing area ratio, curvature ratio, and inflow Reynolds number increase the diffuser performance. The turning angle plays an important role in improving the S-shaped diffuser performance. But, the diffuser performance decreases, when the turning angle is larger than $60^{\circ}$ and the flow path changes far than the symmetric path $\left(45^{\circ} / 45^{\circ}\right)$.

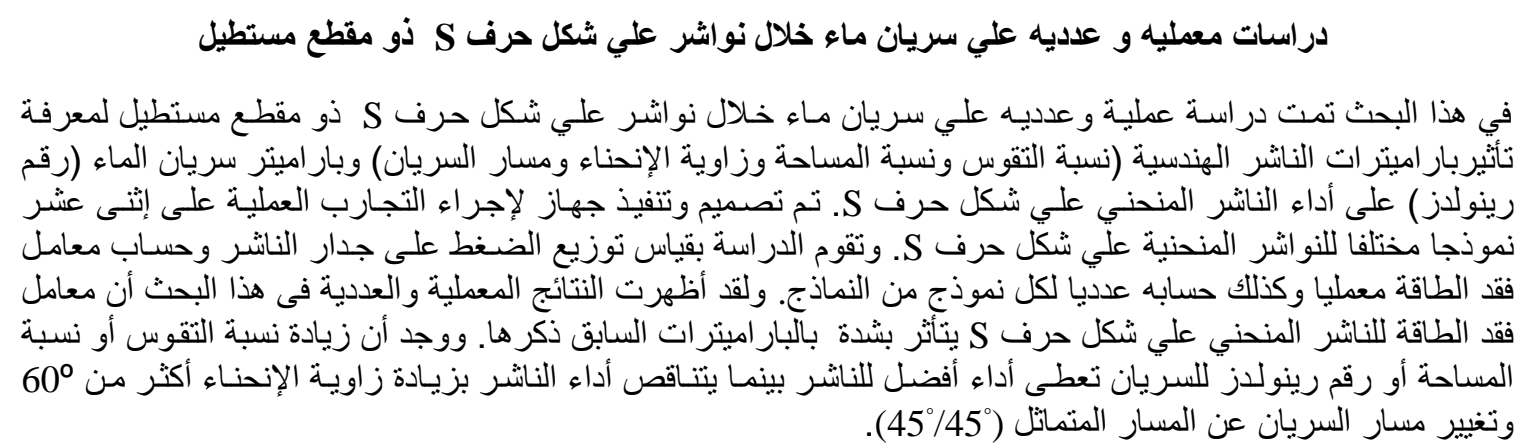

Keywords: Water flow; Diffuser performance; Turn angle; Energy losses; S-Shaped diffusers 
NOMENCLATURE

Symbols

A

AR

B

$W$

$W_{\text {exit }}$

$C_{d}$

$C_{p}$

$C_{p}(I)$

$C_{p_{i}}$

$C_{p_{o}}$

$\mathrm{CR}$

$D_{H}$

$K_{d}$

$p$

$\mathrm{P}_{\text {exit }}$

$\mathrm{P}_{\text {inlet }}$

$Q$

$R_{c}$

$\mathrm{R}_{\mathrm{e}}$

$U_{\text {ref }}$

M...

$\theta_{1}^{\circ} / \theta_{2}^{\circ}$

$U$

$U_{\text {exit }}$

$U_{\text {inlet }}$

$X$

$\Delta H_{o}$ inner wall outer wall
Cross-sectional area, $m^{2}$

S-diffuser area ratio $=A_{\text {exit }} / A_{\text {inlet }}$

$$
\text { Height of the S-shaped diffuser, } m
$$

Curved diffuser inlet width, $m$

Curved diffuser exit width, $m$

Discharge coefficient of the orifice meter

Static pressure recovery coefficient.

Ideal Static pressure coefficient

Static pressure recovery coefficient on the

Static pressure recovery coefficient on the

$\mathrm{S}$-diffuser curvature-Ratio $=R_{c} / W$

Hydraulic diameter, $m$

S-shaped diffuser energy loss coefficient

Pressure, $\mathrm{N} / \mathrm{m}^{2}$

S-shaped diffuser exit Pressure, $N / \mathrm{m}^{2}$

S- diffuser inlet Pressure, $\mathrm{N} / \mathrm{m}^{2}$

Fluid Flow Rate, $m^{3} / s$

Diffuser centre-line arc radius, $m$

Inflow REYNOLDS number

Mean-streamwise velocity at the upstream reference location

Model number

S-shaped diffuser first bend angle / diffuser second bend angle

Water axial velocity inside the diffuser parallel to the diffuser centerline, $\mathrm{m} / \mathrm{s}$

S- diffuser exit flow velocity, $\mathrm{m} / \mathrm{s}$

S-shaped diffuser inlet flow velocity,

$V_{\text {inlet }}=U_{\text {ref }} \mathrm{m} / \mathrm{s}$

Distance along diffuser centerline, measured from the reference location, $m$

the mercury head-difference in the mercury Utube manometer, $\mathrm{m}$

\section{Greek symbols}

$\mu_{w} \quad$ Dynamic viscosity, $K g / m . s$

$v \quad$ Kinematic viscosity, $\mathrm{m}^{2} / \mathrm{s}$

$\rho_{m} \quad$ Mercury density, $\mathrm{Kg} / \mathrm{m}^{3}$

$\rho_{w} \quad$ Water density, $\mathrm{Kg} / \mathrm{m}^{3}$

$\theta \quad$ Turn angle, degree

\begin{tabular}{ll}
\multicolumn{2}{r}{ Subscripts } \\
inlet & Inlet diffuser conditions \\
exit & Exit diffuser conditions \\
I & Ideal \\
$\mathrm{i}$ & Inner wall (Convex wall) \\
$o$ & Outer wall (Concave wall) \\
$\mathrm{p}$ & Pressure recovery \\
$r e f$ & Reference value \\
$x$ & Location value \\
1 & S-shape diffuser first bend \\
2 & S-shape diffuser second bend
\end{tabular}

List of abbreviations

FP S-shaped diffuser flow path

TA S-shaped diffuser turn angle

WP Wetted perimeter, $\mathrm{m}$

CFD Computational Fluid

EXP Experimental data

\section{List of chemical symbols}

\section{$\mathrm{CCL}_{4} \quad$ Carbon Tetra Chloride}

\section{INTRODUCTION}

S-shaped curved diffusers are necessary in fluid flow to decelerate and turn the fluid simultaneously. S-shaped diffusers are used in vaned diffusers of centrifugal pump passages, in steam turbine and in the interconnecting ducts between the components of the gas turbines. They are also used as an aircraft intake ducts, commercial and military aircrafts. Commercial aircraft uses ducts (including S-duct) to allow the thrust vector from rear mounted engines to be aligned with the axis of the aircraft. Military aircraft uses diffusing S-ducts to allow a reduction in the overall aircraft length and to decrease the strength of the radar waves returned in the direction of their origin. Pressure gradients, resulting from streamline curvature, can produce significant secondary flows. Additionally, the adverse streamwise pressure gradient, caused by increasing crosssectional area, can lead to flow separation. Flow separation in S-duct will cause flow distortion, which can result in high cycle fatigue, generated by unsteady dynamics loads. 
The ability to quickly predict complicated flow phenomena without experimental testing is obviously desirable for designers. Therefore, different studies were considered previously.

Literature review on single phase flow through $\mathrm{S}$ shaped curved diffuser, $[1,2]$, indicates that the overall pressure recovery coefficient of the S-shaped diffuser increases by increasing the inflow Reynolds number, the turbulence intensity, area ratio and curvature ratio. S-shaped diffuser flow constitutes the most complex type of flows because there are rotational and three dimensional flows in small aspect ratio. Consequently, S-shaped diffuser flows are difficult to investigate both experimentally and numerically. S-shaped curved diffuser of varying lengths and aspect ratios has been employed in the past to study the streamline curvature effects and secondary motions in single phase flows. One of the main features of flow in S-shaped curved diffuser is the presence of centrifugal force (because of the curvature) which gives rise to the radial pressure gradient normal to the streamline direction that varies inversely with the radius of curvature of the streamline and consequently pressure driven secondary motion.

Curvature also affects turbulence structure (i.e., the Reynolds stresses) and hence the stress-driven secondary flows is much smaller and may not be observable [3]. Generally, the literature considered developing flow in S-shaped curved diffusers to study the effects of S-diffuser parameters on the diffuser performance.

Reneau et al. [4] studied the design and performance of curved diffusers. They concluded; that for the same flow conditions, pressure recovery coefficient and efficiency of curved diffuser are lower than that of straight diffuser.

Bansod and Bradshaw [5] noticed that streamwise favorable pressure gradient exists after the second bend. While secondary flow separation of the boundary layer is generated on the far side of second bend for S-duct.

The mean flow field in a diffusing bend of 40 degrees was measured by McMillan [6]. He found that; as a result of adverse pressure gradient there are secondary flows causing a flow momentum boundary layer fluid on the inner wall (convex wall). A low-speed fluid in the boundary layer on the top and bottom walls is forced towards the convex wall by the pressure gradient and continuity of flow accelerates the fluid in the central portion of the channel towards the concave wall causing secondary cells.

Taylor et al. [7, 8] studied the developing flow in Sshaped ducts of square and circular cross-sections.
They found that; pressure-driven secondary flows arise in the first bend of the duct and near the outer wall of the second bend.

Sullerey [9] performed a comparison between straight diffuser and curved diffuser. He concluded that the straight diffuser performance is higher than that of curved diffuser and with increasing the freestream turbulence the pressure recovery coefficient for each type increases.

The velocity and the pressure characteristics of the water flow in an S-shaped diffusing duct with asymmetric inlet conditions have been measured by Whitelaw and $\mathrm{Yu}$ [10] and simulated by Whitelaw and $\mathrm{Yu}$ [11]. The results showed that the NavierStokes equations are appropriate to predict the details of the near wall flows and rapid flow distortion which it is noticed in the second half of the S-duct.

Turbulent flow velocity characteristics in a round cross-sectional S-shaped diffusing duct were measured by Whitelaw and $\mathrm{Yu}$ [12]. They found that; the region of separation is shown or exist with two thicknesses of inlet boundary layers, and is larger with the thinner inlet boundary layer.

Studies to clarify the flow behavior in S-shaped duct are introduced by Britchford et. al. [13, 14]. They indicated that the flow within the S-shaped duct is significantly influenced by the effects of streamwise pressure gradients and flow curvature.

The flows through S-shaped annular, inter-turbine diffusers were studied by Glyn [15]. He showed that; the total pressure loss coefficient is low at a swirl angle of approximately 15 degrees.

Anderson et al. [16] performed study on computing separating flows within a diffusion inlet S-duct. They found that: micro-vanes can control distortion level with more improvement to the total pressure recovery.

Bruns et al. [17] performed an experimental investigation of a three-dimensional turbulent boundary layer in an ' $\mathrm{S}$ '-shaped duct. They showed that the reverse of the curvature leads to the crossover of the transverse velocity component near the side walls.

Gupta et al. [18] studied the effect of aspect ratio and curvature on characteristics of S-shaped rectangular diffusers using CFD. They showed that; the uniformity of longitudinal velocity and the

pressure coefficient decrease with increase in the diffuser turn angle.

A comparative study of RANS models was performed by Garbaruk et al. [19] on the same S- 
shaped duct studied in Bruns et al. [17]. They found that; high ratings of the S-A model, which are based on the results of calculations of two-dimensional boundary layers.

Gopaliya et al. [18] performed computational studies on analysis of performance characteristics of $\mathrm{S}$ shaped diffuser with offset. They concluded that; the pressure recovery coefficient $\left(\mathrm{C}_{\mathrm{p}}\right)$ decreases with increase in offset. Increasing Reynolds number leads to increase of $\mathrm{C}_{\mathrm{p}}$.

Sinha et al. [19] used computional fluid dynamics (CFD) to improve the performance characteristics of an S-shaped rectangular diffuser by momentum injection. They concluded that; delay in separation results in improved pressure recovery coefficient and the total pressure loss coefficient decreases.

The turbulent flow inside a combined bend-diffuser configuration with a rectangular cross section was experimentally and numerically studied by ElAskary and Nasr [20]. They showed that; there is an optimum diffuser angle which depends on the inflow Reynolds number and produces the minimum pressure loss and hence good performance of such complex geometry is obtained.

CFD analysis of performance characteristics of Sshaped diffusers with combined horizontal and vertical offsets was conducted by Gopaliya et al. [21]. They concluded that; non-uniformity increases in case of S-shaped diffuser with rectangular outlet and with semi-circular outlet. also increase in Reynolds number leads to increase in outlet pressure recovery for both types of diffuser under study.

Sinha and Majumdar [22] investigated numerically and experimentally the flow through annular curved diffusers. They concluded that; the pressure coefficient increases sharply with area ratio and the standard k- $\varepsilon$ model is the suitable one for simulation.

Numerical validation of flow through an S-shaped diffuser was performed by Das et al. [23]. They showed that; high velocity is shifted towards outer wall due to generation of secondary motion, which caused due to the combined effect of the centrifugal action of the center-line curvature and adverse pressure gradient.

Turning angle effect on the flow through a diffusing S-duct was conducted by Abdellatif et al. [24]. They concluded that: separation regions are characterized with high turbulence levels and occur near the convex wall of the S-duct first bend and increased by the increase of turning angle, which hardly affects the pressure coefficient. Biswas et al. [25] investigated the flow in a constant area rectangular curved duct. They concluded that; wall pressures minimum and maximum occur at the inner and the outer walls respectively under influence of curvature radius and turn angle of the curved duct. Also flow at exit is purely non-uniform in nature due to the strong secondary motion.

Experimental flow investigation of curved diffuser was conducted by El-Askary et al. [26]. They concluded that: outer wall pressure coefficient is higher than that the inner wall and the S-shaped diffuser energy-loss coefficient, $K_{d}$, is found to be inversely proportional to the generalized Reynolds number, diffuser area ratio and diffuser curvature ratio.

Experimental and computational studies on S-duct diffuser were conducted and various combinations of submerged-vortex generators (SVG) were tested by Pau et al. [27]. They concluded that; as skewed inflow condition, the outflow of the S-duct diffuser is distorted and reduces the duct performance so using submerged-vortex generators makes the flow more uniform at diffuser exit.

The effect of momentum imparting on different performance characteristics of S-shaped diffuser has been studied by Gopaliya et al. [28]. They concluded that: momentum imparting increases the exit static pressure coefficient of the S-shaped diffusers and the non-uniformity at diffuser exit decreases by placing a rotating cylinder across the $\mathrm{S}$ - diffuser width.

The focused literature review indicated the importance of studies performed on S-diffuser and curved-diffuser. However, the first type has a narrow space of studies, either experimental or numerical.

The main objective of the present work is to gain insight into the rectangular $\mathrm{S}$-shaped curved diffuser performance carrying water. The effects of the inflow Reynolds number and the geometrical parameters of the S-shaped curved diffuser such as the area ratio, curvature ratio, flow path and turning angle are considered in order to extract general conclusions. First, outer and inner wall static pressure distributions are experimentally measured and compared with the numerically predicted values. Based on the measured and computed wall-pressure distributions the S-shaped diffuser loss coefficient will be extracted and discussed under different inflow and geometrical conditions.

\section{Analytical Study}

The energy equation applied between the entrance (inlet) and exit of the S-shaped diffuser reads: [26]

$$
h_{\text {inlet }}+\frac{U_{r e f}^{2}}{2 \mathrm{~g}}=h_{\text {exit }}+\frac{U_{\text {exit }}^{2}}{2 \mathrm{~g}}+\mathrm{h}_{\text {loss }}
$$




$$
\begin{aligned}
& h_{\text {loss }}=\left(h_{\text {inlet }}-h_{\text {exit }}\right)+\frac{\left(U_{r e f}^{2}-U_{r e f}^{2} / \mathrm{AR}^{2}\right)}{2 \mathrm{~g}} \\
& h_{\text {loss }}=\frac{\left(P_{\text {inlet }}-P_{\text {exit }}\right)}{\rho_{w} \mathrm{~g}}+\frac{U_{r f}^{2}\left(1-1 / \mathrm{AR}^{2}\right)}{2 g}
\end{aligned}
$$

With $h_{\text {inlet }}$ and $h_{\text {exit }}$ are the pressure heads at inlet and exit of the S-shaped diffuser, respectively, while $\boldsymbol{U}_{\boldsymbol{r e f}}$ and $U_{\text {exit }}$ are the time-averaged mean velocities at diffuser inlet and exit, respectively and $\rho_{w}$ is the water density. The pressure coefficient is:

$$
C_{p}=\frac{\left(P_{x}-P_{r f}\right)}{0.5 \rho_{w} U_{r f}^{2}}
$$

Where, $P_{x}$ is the measured local wall pressure, $P_{r e f}$ is the reference pressure which is taken as diffuser inlet pressure on outer-wall, whereas the reference location (position zero point; $x=y=z=0 \mathrm{~m}$ ) is taken at the diffuser entrance on inner-wall. The loss coefficient $\left(\mathrm{K}_{\mathrm{d}}\right)$ can then be determined from this equation:

$$
\mathrm{K}_{d}=\left(\boldsymbol{C}_{p \text { (inlet) }}-\boldsymbol{C}_{p(\text { exit })}+1-A R^{-2}\right)
$$

From which the loss head can be computed as:

$$
\mathrm{h}_{\text {loss }}=K_{d} \frac{U_{r e f}^{2}}{2 \mathrm{~g}}
$$

Where $\boldsymbol{C}_{p \text { (inlet) }}$ and $\boldsymbol{C}_{p(\text { exit })}$ are the pressure coefficients at inlet and exit of the S-diffuser, respectively and $A R=A_{\text {exit }} / A_{\text {inlet }}$ is the diffuser area ratio. The area ratios for the considered geometries are: $A R=3$ for models $1,7,8$ and 9, while $A R=2$ for models 2, 4, 5, 6, 10, 11 and 12, and $A R=1.5$ for model 3, see Table 1 .

\section{EXPERIMENTAL SETUP AND PROCEDURE}

Fig. 1 shows the test rig (Schematic and Photograph, Fig. 1.a, c,) including the S-diffuser test section, Fig. 1.b, of constant height $(\mathrm{B}=80 \mathrm{~mm})$, inlet width (W=20 mm), upstream tangent duct length of $40 \mathrm{DH}$ and downstream tangent duct length of $50 \mathrm{DH}$. The convex / concave radius of curvature $\left(R_{c}\right)$ varies from 100 to $250 \mathrm{~mm}$ according to the tested model, see Table 1. Different exit widths $\left(W_{\text {exit }}\right)$ of 30, 40 and $60 \mathrm{~mm}$ are considered; see Fig. 1-b, c for controlling the area ratio. The water is prepared from tap water in a large tank of $0.5 \mathrm{~m} 3$ capacity, then it is circulated through the test rig using a centrifugal pump of $2 \mathrm{~kW}$ power. The flow rate is measured by a calibrated orifice meter. Multi-tube manometer is used to measure static pressure distributions along the outer and inner walls of the S-shaped curved diffusers (test sections), the upstream and downstream tangents. The measuring fluid used in the manometer is Carbon Tetra Chloride $\left(\mathrm{CCL}_{4}\right)$. This liquid does not mix with water and has specific gravity of 1.4. By using this liquid the static pressure at each tapping hole can be measured by the difference-head of the used measuring liquid.

\section{UNCERTAINTY ANALYSIS}

Before being documented for any analysis or design, the data obtained from experimental studies should be validated. The experimental errors may be of two types, namely fixed and random errors. Fixed error can be removed by proper calibration or correction while random error cannot be removed. The factors that introduce random error are uncertain by their nature. Uncertainty analysis should be conducted on all data collected from all measurements in order to quantify the data and validate the accuracy. As known, the flow resistance coefficient of the tested S-shaped diffuser, $K_{d}$ (S-shaped diffuser energyloss coefficient) is given by equation (7) as:

$K_{d}=h_{\text {loss }} \frac{2 g}{U_{r f}^{2}}=h_{\text {loss }} \frac{2 g}{(Q / A)_{r f}^{2}}=h_{\text {loss }} \frac{2 g B^{2} W^{2}}{Q^{2}}$

in which, $Q$ is the volume flow rate measured by calibrated orifice meter and $h_{\text {loss }}$ is the loss head through the S-diffuser. The precision uncertainty of $K_{d}$ is due to uncertainties for all independent variables of them. The precision uncertainty $\left(\delta \mathrm{K}_{d} / \mathrm{K}_{d}\right)$ can be represented as indicated in Taylor [28]:

$\frac{\delta \mathrm{K}_{d}}{\mathrm{~K}_{d}}= \pm\left\{\begin{array}{l}\left(\frac{h_{\text {loss }}}{K_{d}} \frac{\partial K_{d}}{\partial h_{\text {loss }}} \frac{\delta h_{\text {loss }}}{h_{\text {loss }}}\right)^{2}+\left(\frac{B}{K_{d}} \frac{\partial K_{d}}{\partial B} \frac{\delta B}{B}\right)^{2} \\ +\left(\frac{W}{K_{d}} \frac{\partial K_{d}}{\partial W} \frac{\delta W}{W}\right)^{2}+\left(\frac{Q}{K_{d}} \frac{\partial K_{d}}{\partial Q} \frac{\delta Q}{Q}\right)^{2}\end{array}\right\}^{1 / 2}$

Where, $\delta h_{\text {loss }} / h_{\text {loss }}, \delta B / B, \delta W / W$ and $\partial Q / Q$ are the precision uncertainties for independent variables $h_{\text {loss }}, B, W$ and $Q$, respectively. The reasonable estimate of the uncertainty intervals due to random error in the present experimental study is taken as plus or minus half the smallest scale division (the 
least count) of the instrument used in conducting the measurement. Thus, $\delta h_{\text {loss }}, \delta B$ and $\delta W$ are taken to be $0.5 \mathrm{~mm}$. The discharge $\mathrm{Q}$ is measured using the calibrated orifice meter and calculated from the orifice meter equation as follows:

$$
Q=C_{d} \frac{A_{o} A_{p}}{\sqrt{A_{p}^{2}-A_{o}^{2}}} \sqrt{2 g \Delta H_{o} \frac{\rho_{m}-\rho_{w}}{\rho_{w}}}
$$

Where $C_{d}$ is the orifice discharge coefficient, Ao is the orifice area, Ap is the pipe cross- section area, $\Delta H_{o}$ is the mercury head-difference in the mercury U-tube manometer and $\rho_{m}$ is the mercury density in the manometer. The precision uncertainty of the discharge $(\delta Q / Q)$ can be computed as:

$$
\frac{\delta Q}{Q}= \pm\left\{+\left(\begin{array}{l}
\left(\frac{\Delta H_{o}}{Q} \frac{\partial Q}{\partial \Delta H_{o}} \frac{\delta \Delta H_{o}}{\Delta H_{o}}\right)^{2} \\
\left.\frac{\partial Q}{\partial D_{P}} \frac{\delta D_{P}}{D_{P}}\right)^{2} \\
+\left(\frac{d_{O}}{Q} \frac{\partial Q}{\partial d_{o}} \frac{\delta d_{O}}{d_{O}}\right)^{2}
\end{array}\right\}\right.
$$

Thus, the precision uncertainties of the energy-loss coefficient can be obtained. Table 2 presents the range of energy loss coefficient and percentage precision uncertainty of resistance coefficient $\left( \pm U_{k_{d}} \%\right)$ during all measurements.

\section{NUMERICAL STUDY}

In the present study, CFD simulations are carried out using ANSYS R-15.0 with software Fluid Flow Fluent (FFF) which applies 3D-RANS (Reynolds Averaged Navier-Stokes equations) method. Preliminary investigations are done using a range of turbulence models to validate the CFD code with the experimental data obtained for all tested $\mathrm{S}$ diffuser models of rectangular cross-section. The flow field is predicted using three turbulence models namely, standard $\mathrm{k}-\omega(\mathrm{S}-\mathrm{K}-\omega)$, shear stress transport $\mathrm{k}-\omega(\mathrm{SST}-\mathrm{K}-\omega)$ and standard $\mathrm{k}-\varepsilon(\mathrm{S}-\mathrm{k}-\varepsilon)$ models. The comparisons with the present measurements show that the pressure coefficient profile is successfully predicted using the last turbulence model (S-k-E), see Fig. 2. Therefore, the $\mathrm{S}-\mathrm{k}-\varepsilon$ model is used as a solution turbulence model for simulating the water flow with maximum $\mathrm{Re}$ $=34000$ based on inlet hydraulic diameter of $32 \mathrm{~mm}$ and maximum average velocity at diffuser inlet $=1.07 \mathrm{~m} / \mathrm{s}$. In order to predict the flow in the $\mathrm{S}$ - shaped diffuser accurately, it is important to ensure that the inlet conditions match with the solver.

\subsection{Resolution Effects}

The computations of S-diffuser with its two tangents (upstream and downstream) are carried out for different grid sizes (mesh cells of 500000, 1080000 and 1500000 cells, see Fig. 3.a) and static pressure coefficient was monitored for each grid with experimental measurements. The results indicate that the medium grid (1080000) can be used as it produces suitable data in view of the comparisons with the experimental results of the pressure coefficient, see Fig. 3.b.

\section{RESULTS AND DISCUSSIONS}

In the present study, it is aimed to extract the energy-loss coefficients (flow resistance coefficients) for the S-shaped curved diffusers with different area ratios: $(1.5,2$, and 3$)$, different curvature ratios $\left(C R=R_{c} / W=5,7.5\right.$, and 12.5), different flow paths $\left(45^{\circ} / 45^{\circ}, 60^{\circ} / 30^{\circ}\right.$ and $\left.30^{\circ} / 60^{\circ}\right)$, and different turn angles $\left(45^{\circ} / 45^{\circ}, 60^{\circ} / 60^{\circ}\right.$ and $\left.90^{\circ} / 90^{\circ}\right)$. However, the geometrical parameters of all models of the S-shaped curved diffusers are given in Table 1.

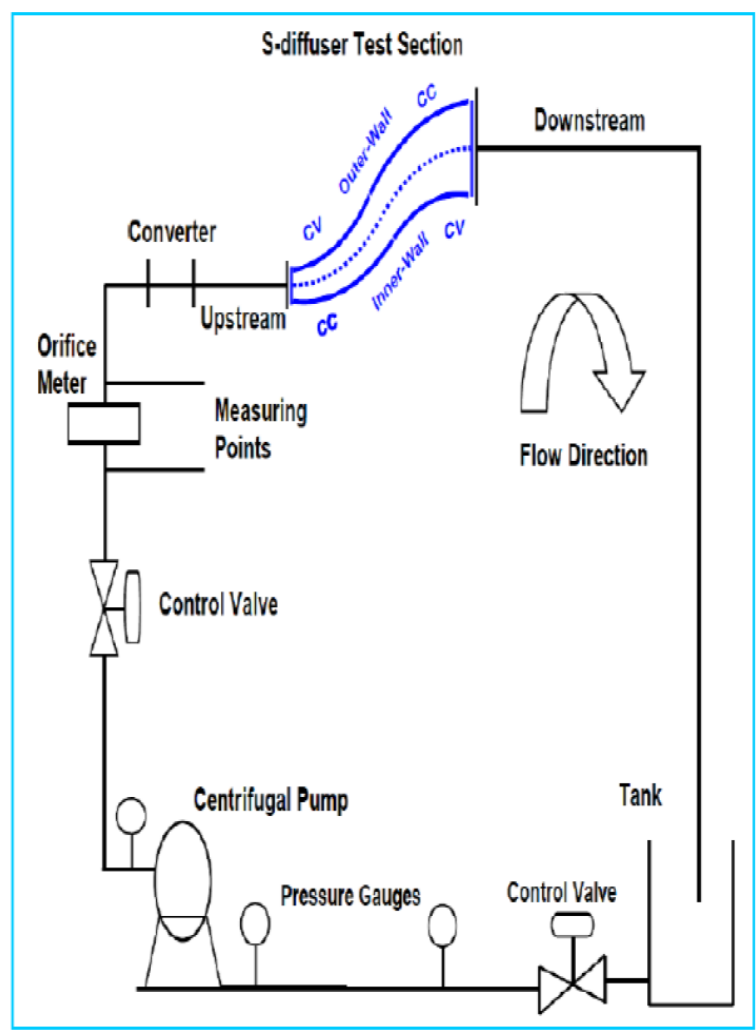

(a) Schematic diagram 


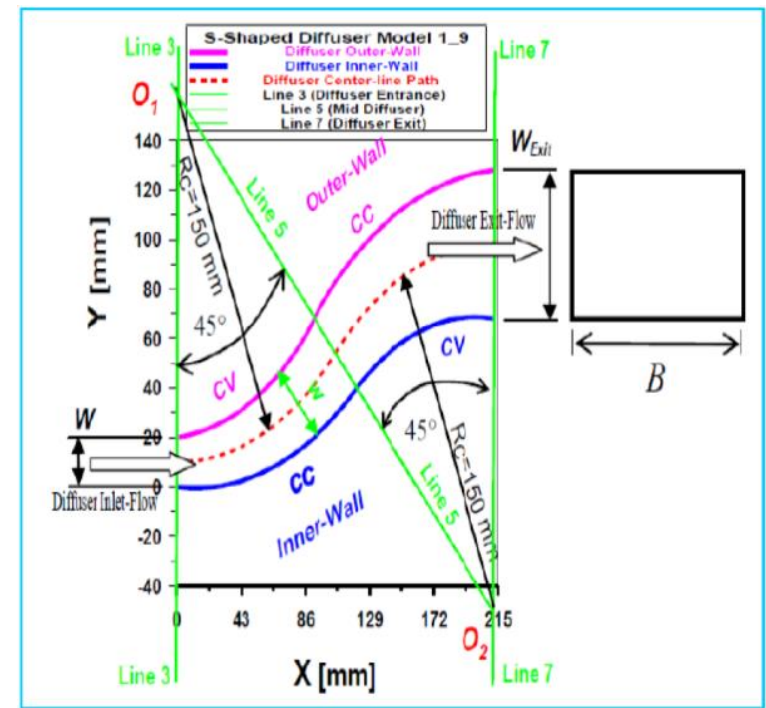

(b)Test section of S-diffuser

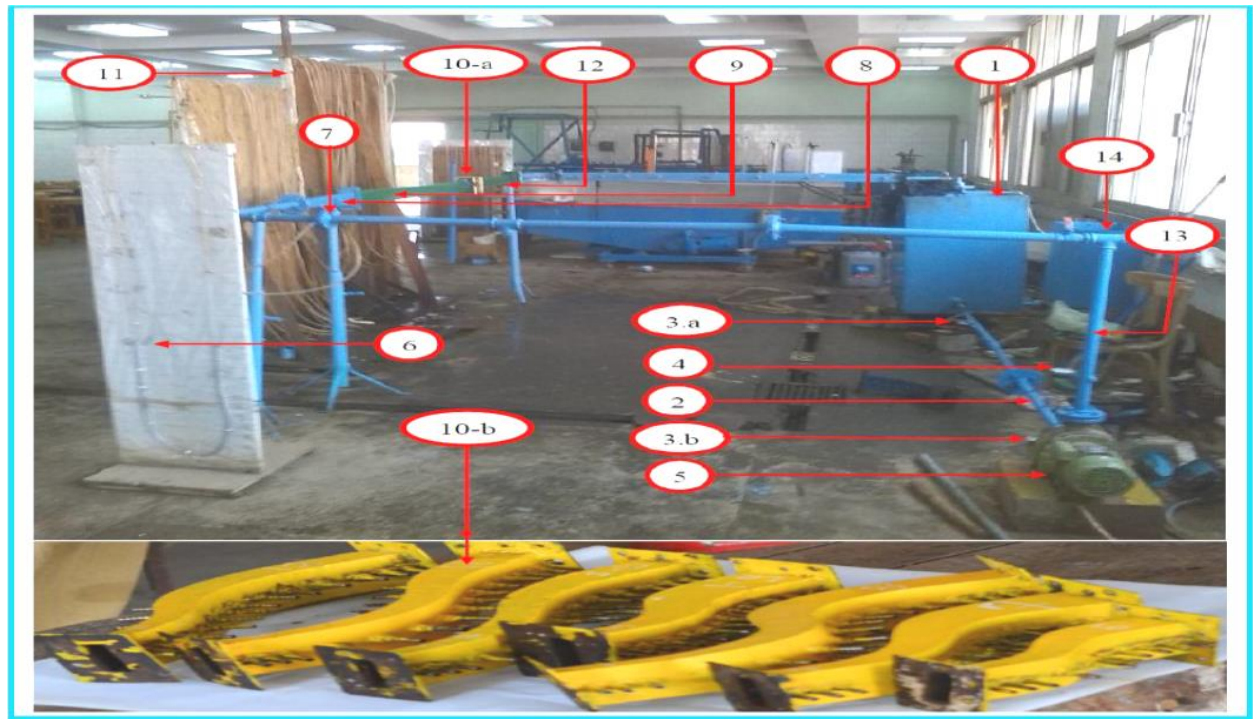
1. Main tank
2. Suction-side pipe
3. Suction pressure gauges
5. Centrifugal pump
6. U-tube manometer
7. Orifice-meter
9. Upstream tangent duct
10. S-diffuser Model.
11. Multi-tube manometer

4. Delivery pressure gauge

8. Converter

12. Downstream tangent duct

14. calibration tank

13. Delivery-side pipe

(c) Photograph of the test rig.

Fig.1. Experimental setup

The results are presented experimentally and numerically for the water flow in S-shaped diffuser as the pressure distributions and hence the $\mathrm{S}$ diffusers energy loss coefficients. Measurements are performed at different diffuser inflow Reynolds numbers range of $9000 \leq \mathrm{Re} \leq 34000$ where $\operatorname{Re}=\left(\rho_{w} U_{r e f} D_{H} / \mu_{w}\right)$ with $D_{H}=[2 W B /(W+B)] \quad$ (the hydraulic diameter). The static pressure and the energy-loss coefficients are affected by inflow
Reynolds number, diffuser area ratio, diffuser curvature ratio, diffuser turn angle and diffuser flow path as the following experimental and numerical studies. All the following computations are based on $\mathrm{S}-\mathrm{k}-\varepsilon$ as a suitable turbulence model for simulations. 


\subsection{Wall Pressure Distributions}

Wall static pressure is measured as stated before in 2.2 , and by applying equation 4 , pressure recovery coefficient is obtained. The experimental and numerical studies are conducted for the twelve Sdiffuser tested models to indicate the effect of inflow Reynolds number (34000, 24000 and $18000)$ on the static pressure recovery coefficient at outer and inner walls of the S-shaped diffusers (Fig. 4). From the results in Fig. 4 it is clear that the static pressure recovery coefficient of the S-shaped diffusers is found to be directly proportional to the diffuser inflow Reynolds number with a noticeable decrease in the adverse pressure gradient inside the S-shaped diffuser. This leads to a decrease of the boundary layer thickness on the walls and hence reduces the chances of separation in the S-shaped diffuser. Therefore, the performance of S-shaped diffuser can improved with accelerating the inflow. Generally, the higher wall pressure distribution is observed on the outer walls of all models, because of the presence of radial pressure gradient generated by the centrifugal force. One notices that there is a distinct reduction of pressure along the outer-wall and the inner-wall of the upstream and downstream tangent ducts of the S-shaped diffuser.

The comparison of experimental data with the computational predicted values of pressure coefficient reveals good agreement between them. This comparison includes the effects of S-diffuser geometrical parameters, area ratio, curvature ratio, turn angle and flow path on the diffuser pressure coefficient at $\mathrm{Re}=34000$ for all tested models as shown in Figs. 5, 6, 7 and 8, respectively.

However, increasing the area ratio causes enhancement of the axial pressure gradients and this can be clearly visible in Fig. 5 in which the walls pressure increases for models 2 and 1 of the higher area ratio. The jump of the inner wall pressure distribution at $\mathrm{X}_{\mathrm{i}} / \mathrm{W}=5$ which is followed by a strong decreases of the pressure to $\mathrm{X}_{\mathrm{i}} / \mathrm{W} \cong 7$, and then a gradual increase may be an indicator of flow separation on that wall. The variations of curvature radius shown in Fig. 6 will strongly affect on the performance of diffuser, whereas the turn angle does not affect the pressure recovery coefficient, see Fig. 7. Fig. 8 shows the pressure recovery coefficient under different diffuser flow paths, which will be discussed later.

\subsection{Diffuser Performance}

In the present section, attempts have been made to understand performance of water flow in S-shaped diffusers through the energy-loss characteristics. The S-shaped diffuser energy-loss coefficient is expressed in terms of diffuser inflow Reynolds number. The energy-loss coefficient of the S-shaped diffusers decreases as the area ratio or the curvature ratio increases as shown in Figs. 9 and 10 respectively. The effect of S-diffuser symmetric turn angle is shown in Fig. 11, and the loss coefficient is observed hardly affected by change of the turn angle (models 7, 8, and 9). The S-shaped diffuser energyloss coefficient is strongly affected by diffuser flow path since it is noticed clearly that it increases with symmetric turn angle and decreases with asymmetric turn angle (models 10, 11, and 12) as shown in Fig. 12. The effect of diffuser inflow Reynolds number (ranged from 9000 to 34000) on the energy-loss coefficient for all S-diffuser tested models is shown in Fig. 13.

From the results in Figs. 9-12 it is noticed that: energy-loss coefficient of the S-shaped diffusers with water flow is found to be inversely proportional to area ratio, curvature ratio, symmetry of the Sshaped diffuser turn angle and inflow Reynolds number. The diffuser energy-loss coefficient approaches asymptotic values for high diffuser inflow Reynolds number. For the same radius of curvature, i.e. an equal main-flow pass, the pressure gain from the widest diffuser (the highest area ratio) is higher than the energy lost due to intensive secondary flows produced; it means that the diffuser energy loss decreases with increasing the area ratio, see Fig. 9.

The main reason of the curvature ratio effects is the decreasing of the centrifugal force created in the Sshaped curved diffuser with increasing the curvature ratio, which is responsible for secondary flow generation, as the curvature ratio decreases the energy loss in the S-shaped diffuser increases for the different flows, because of the generation of strong 
"K. A. Ibrahim, W. A. El-Askary, E. Saker and Hamdy A. Omara, " EXPERIMENTAL AND ..."

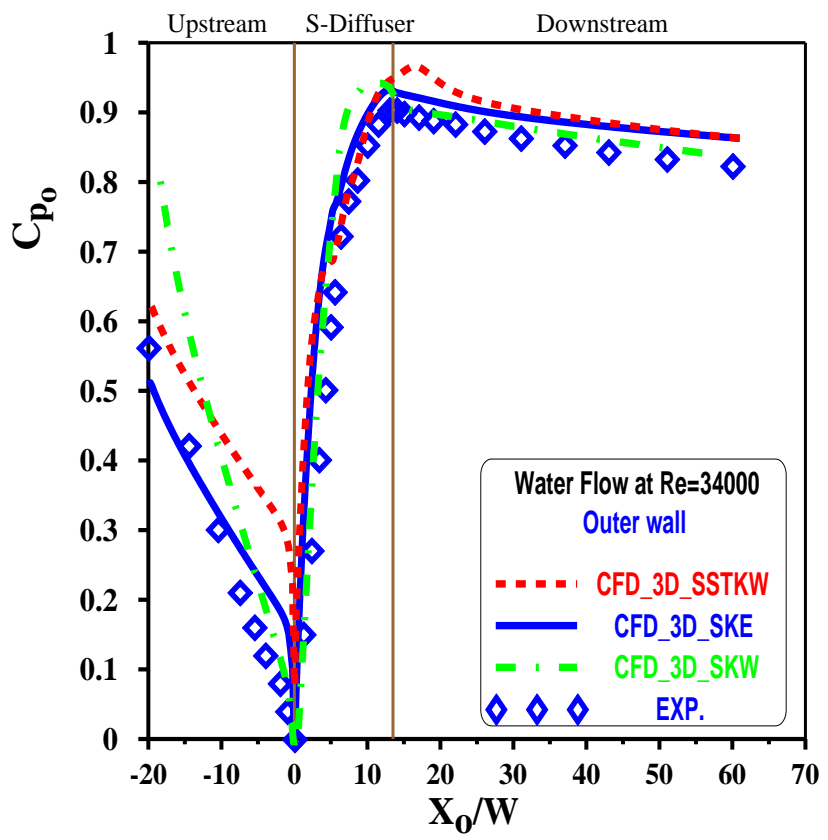

(a) outer-wall

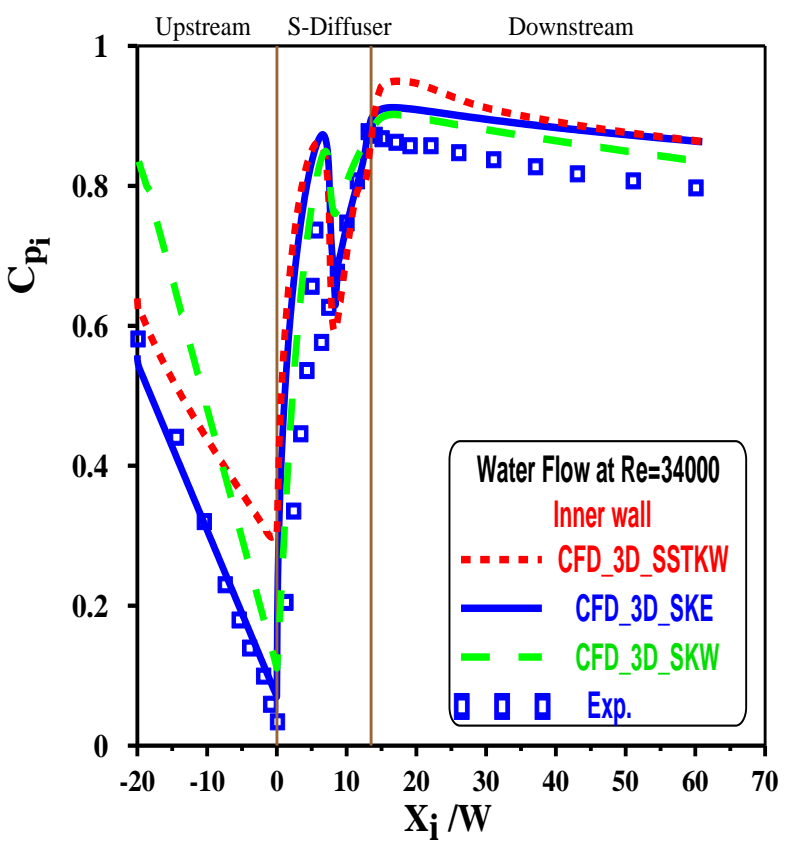

(b) inner-wall

Fig. 2 Pressure coefficient distributions for model 7

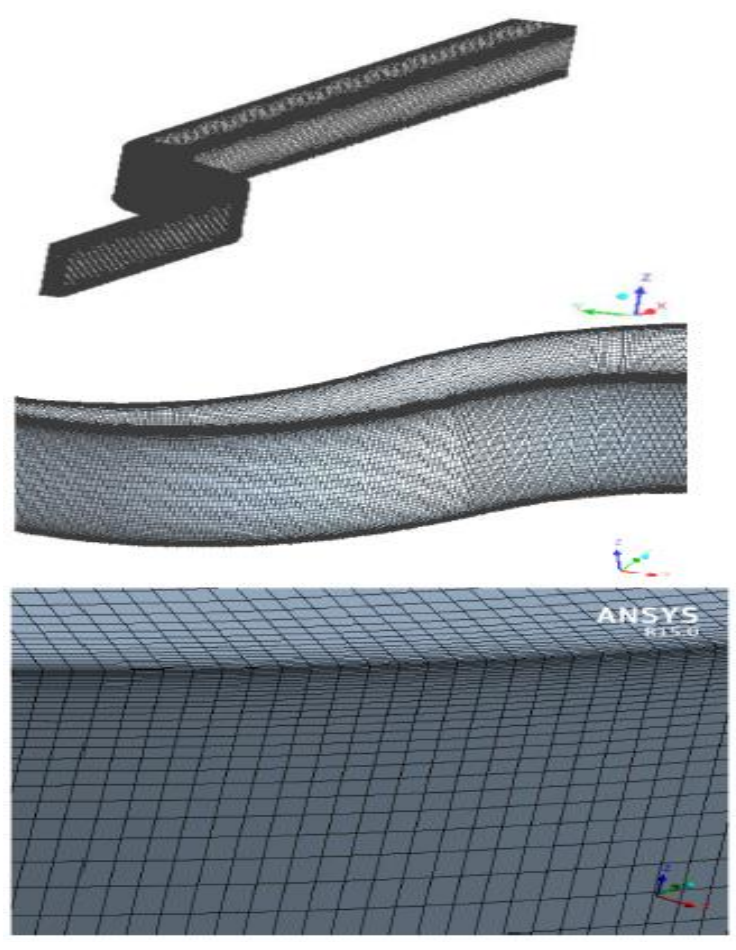

(a) computational grid

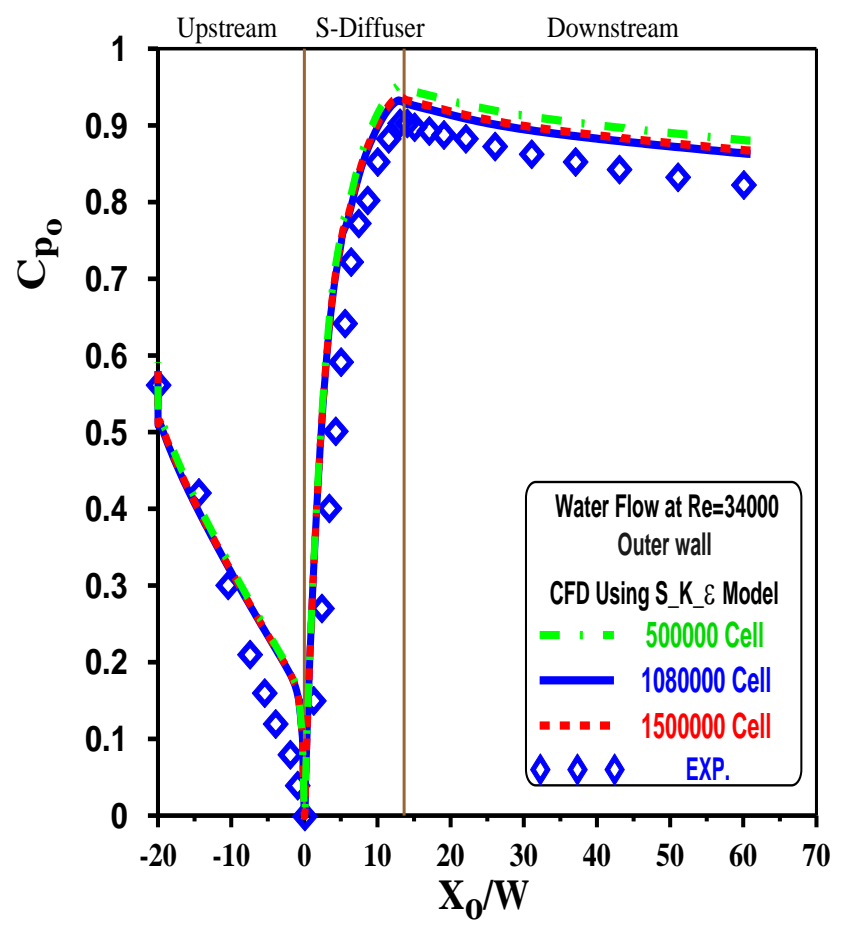

(b) outer-wall pressure coefficient distributions

Fig. 3 Computational grid and resolutions effect on results for model 7 
"K. A. Ibrahim, W. A. El-Askary, E. Saker and Hamdy A. Omara, " EXPERIMENTAL AND ..."

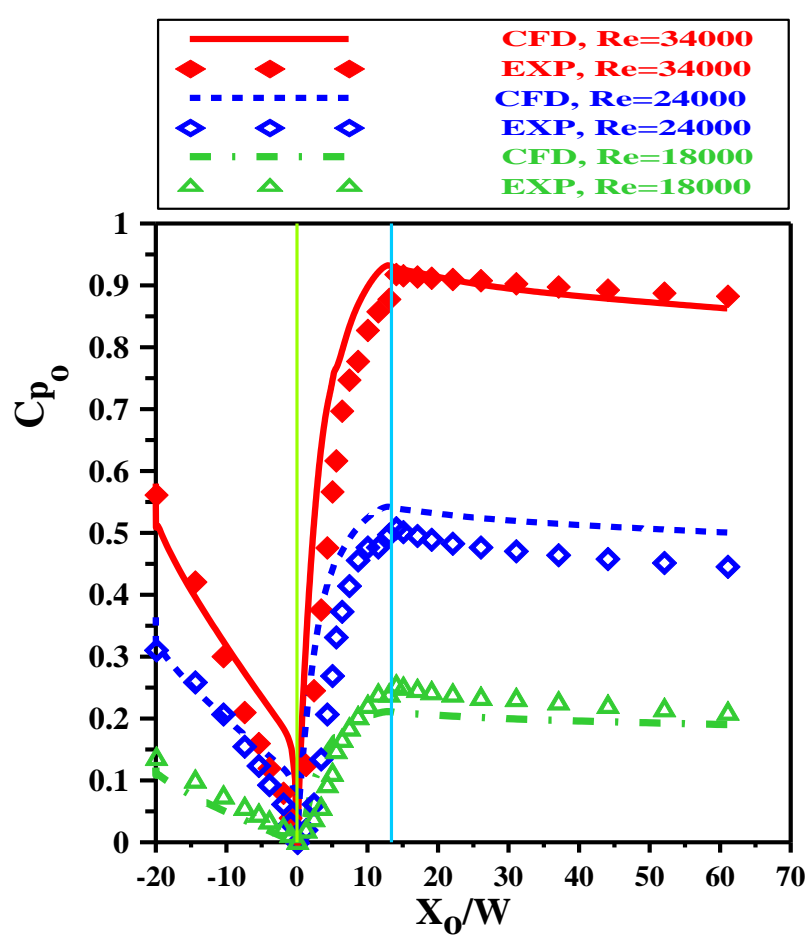

(a) outer-wall

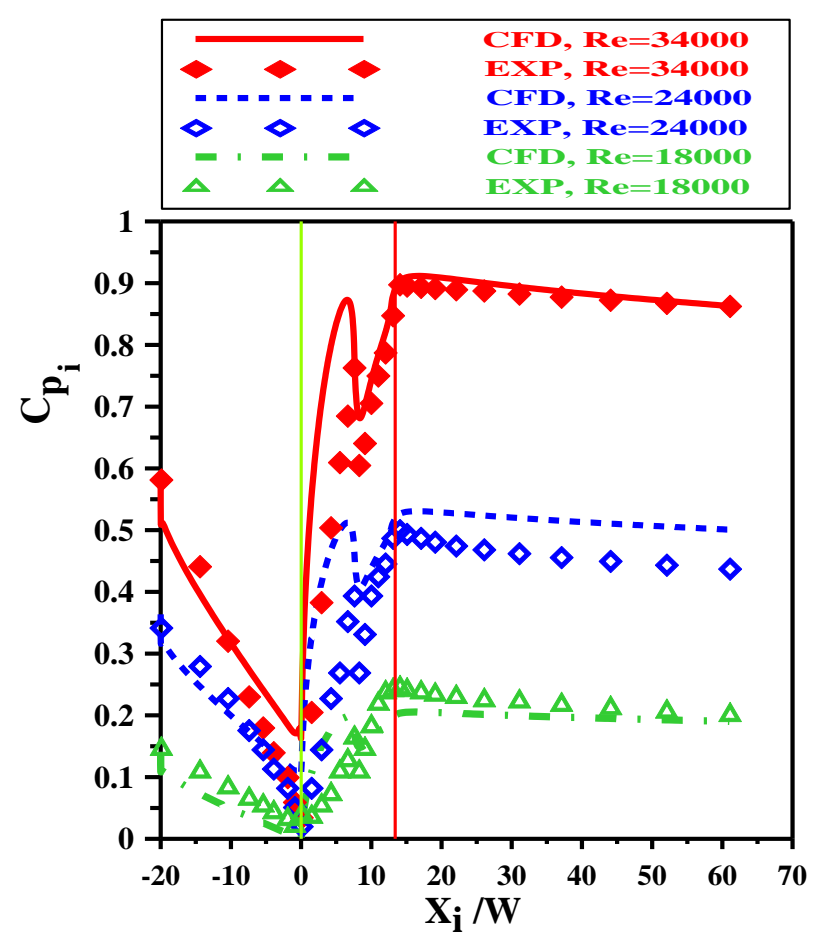

(b) inner-wall

Fig. 4 Effect of Reynolds number on pressure recovery coefficient of model (7)

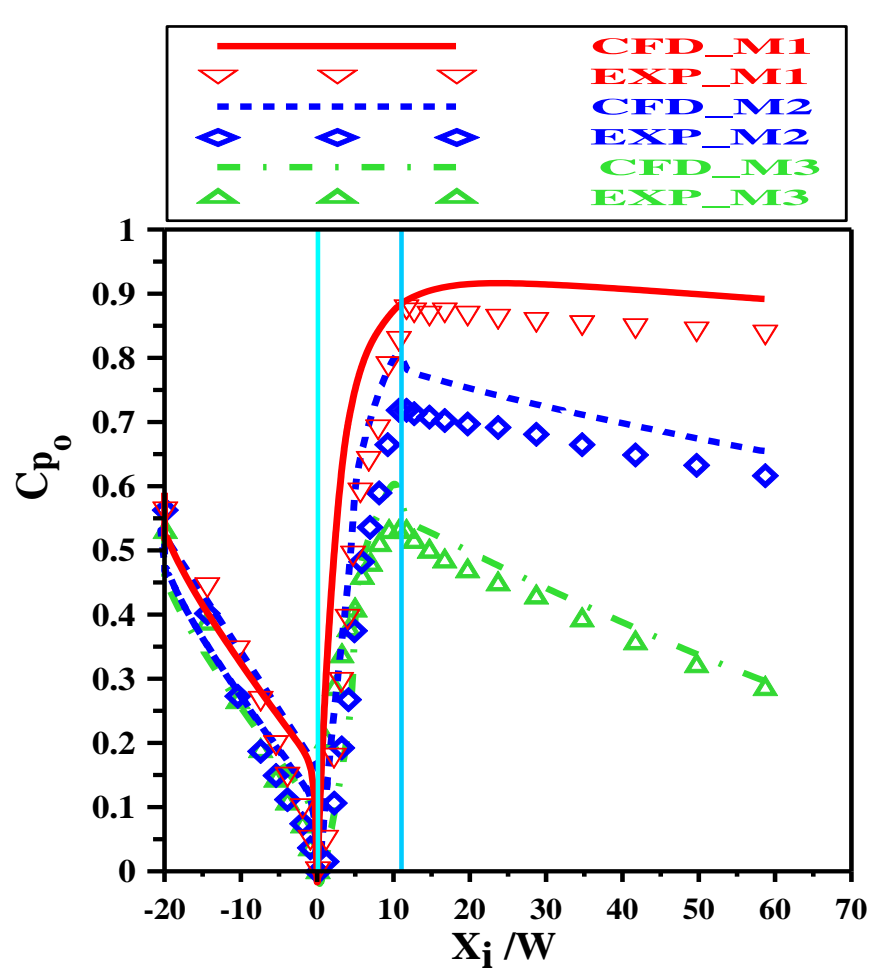

(a) outer-wall

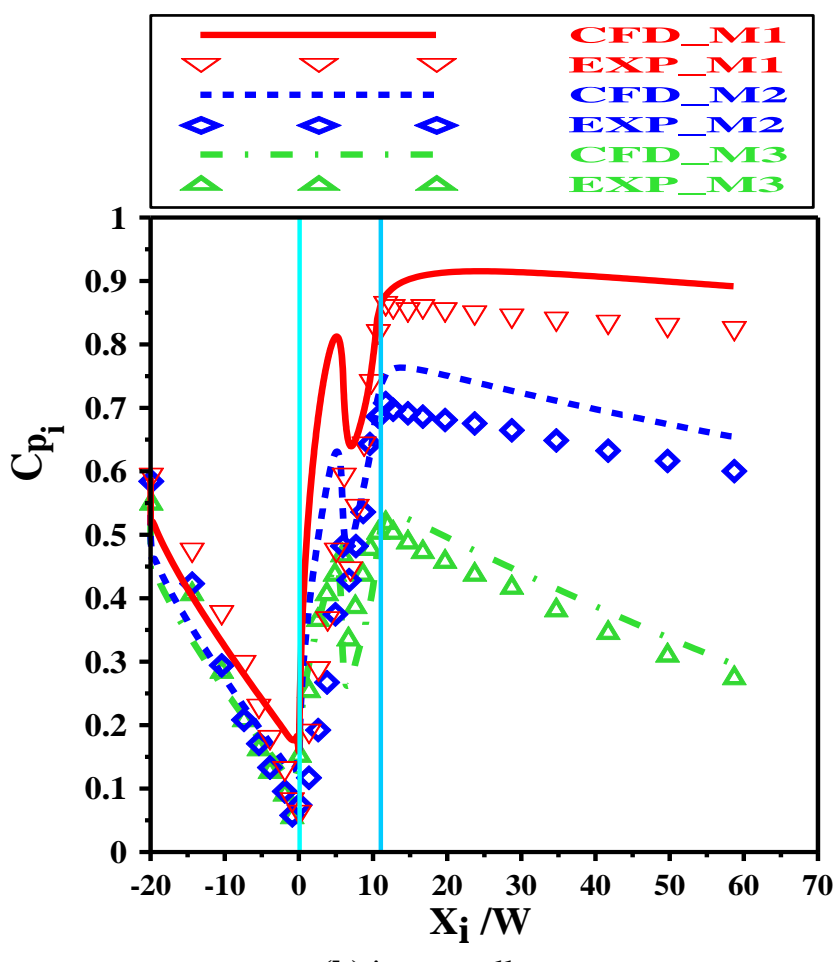

(b) inner-wall

Fig. 5 Effect of S-diffuser area ratio on pressure recovery coefficient at $\operatorname{Re}=34,000$ 


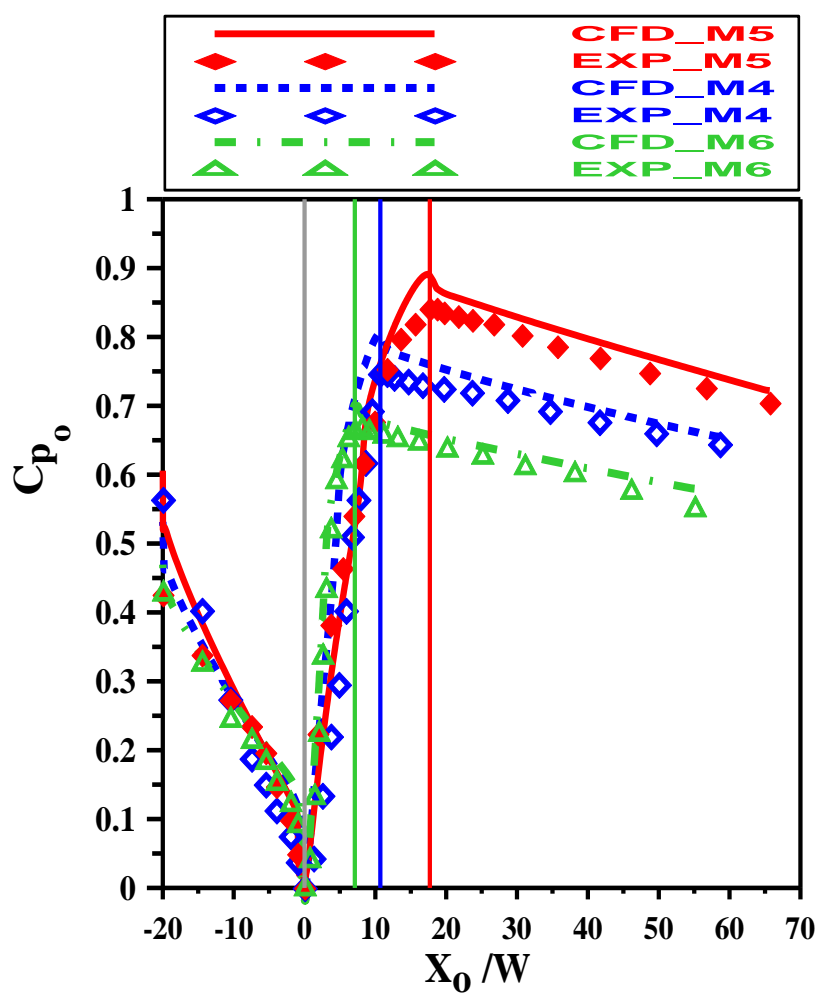

(a) outer-wall

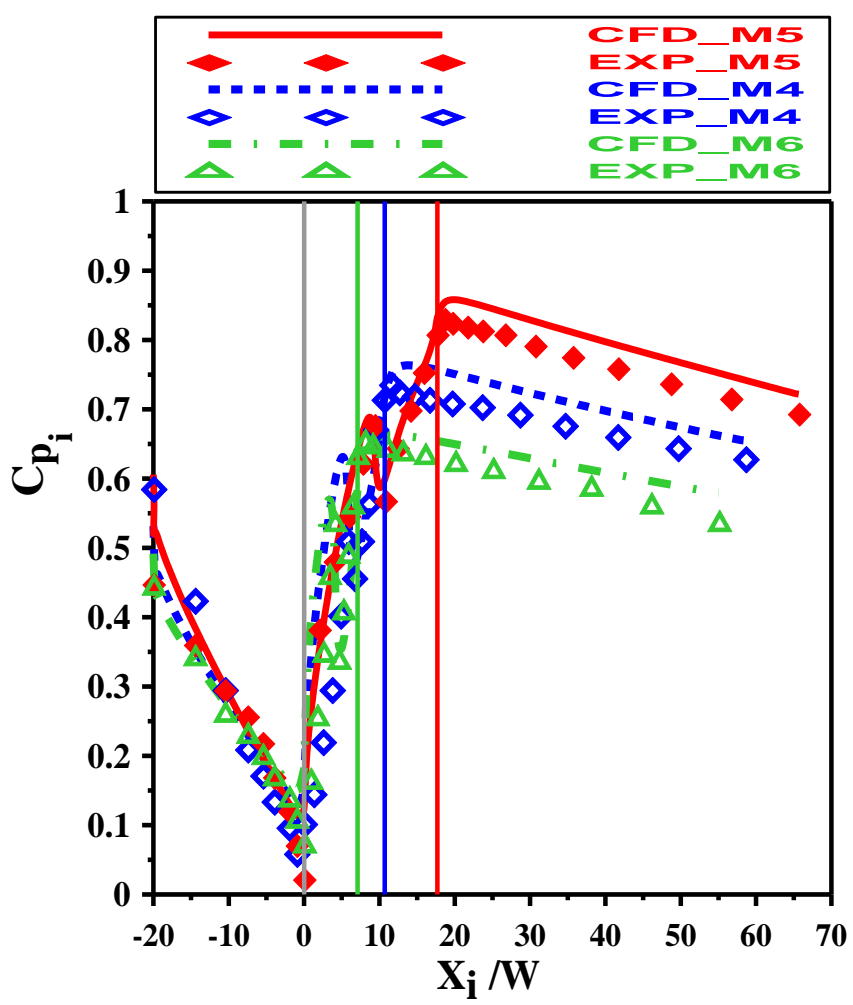

(b) inner-wall

Fig. 6 Effect of S-diffuser curvature ratio on pressure recovery coefficient at $\operatorname{Re}=34,000$

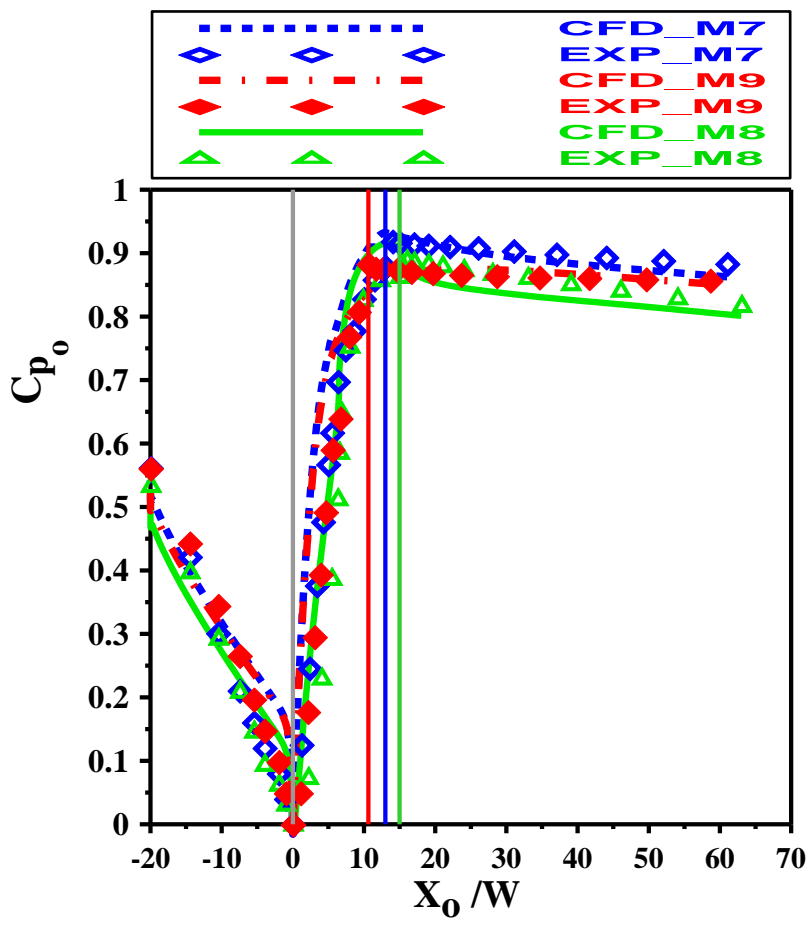

(a) outer-wall

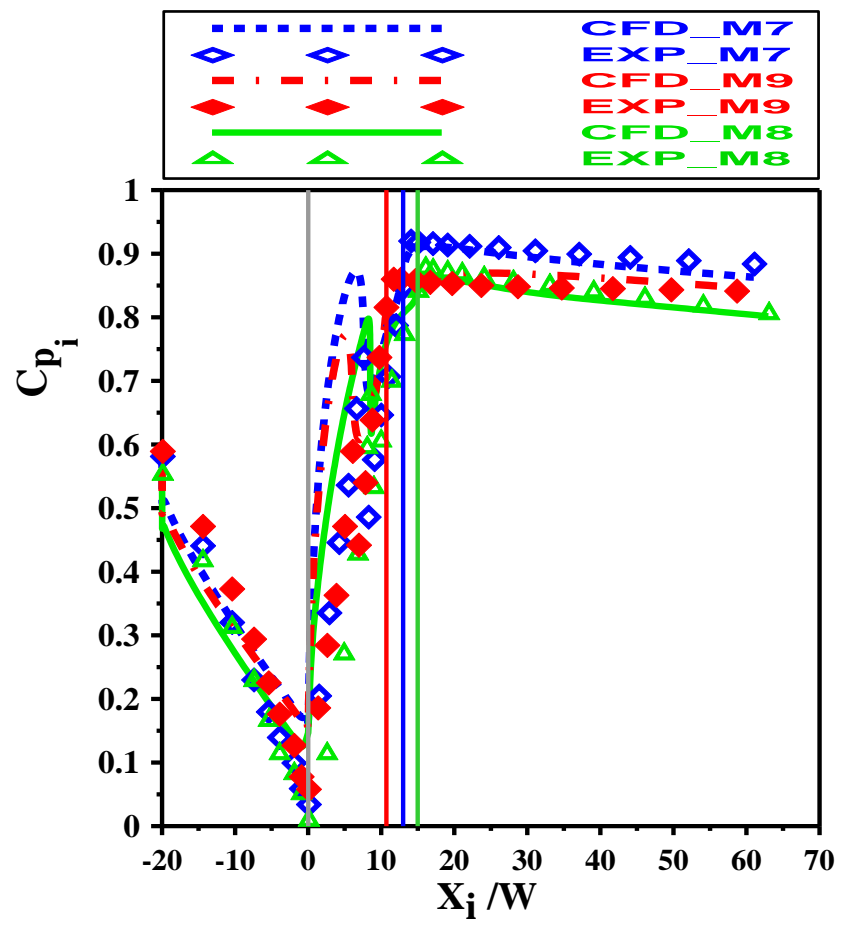

(b) inner-wall

Fig. 7 Effect of S-diffuser turn angle on pressure recovery coefficient at $\operatorname{Re}=34,000$ 
"K. A. Ibrahim, W. A. El-Askary, E. Saker and Hamdy A. Omara, EXPERIMENTAL AND ..."

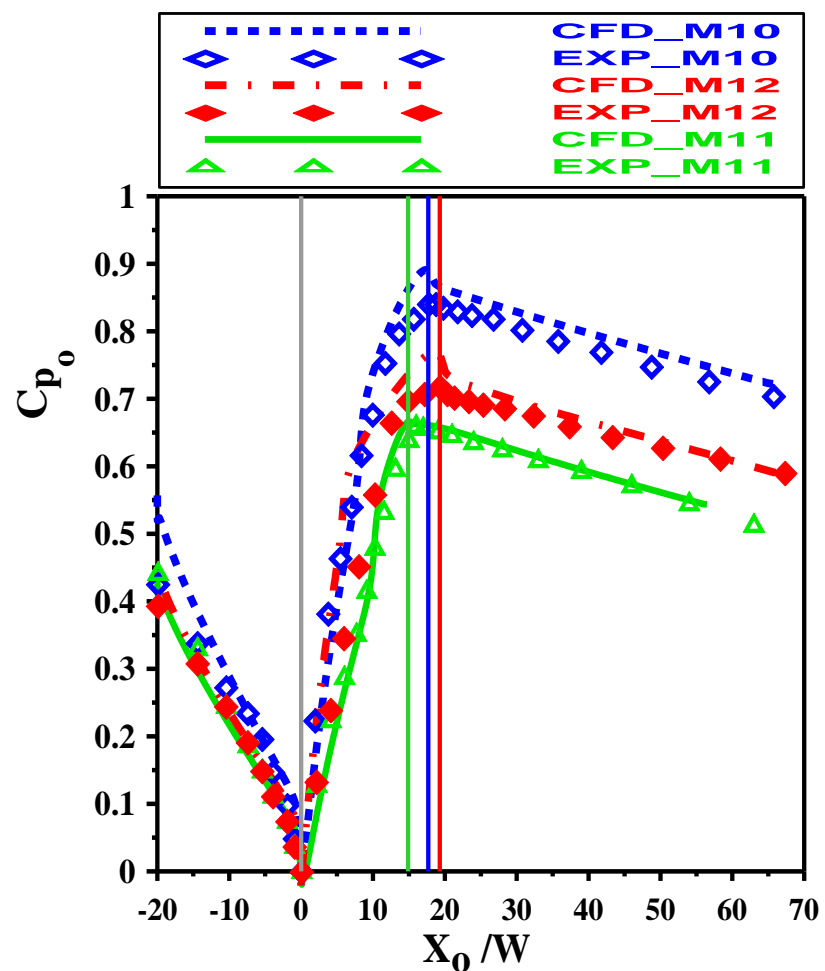

(a) outer-wall

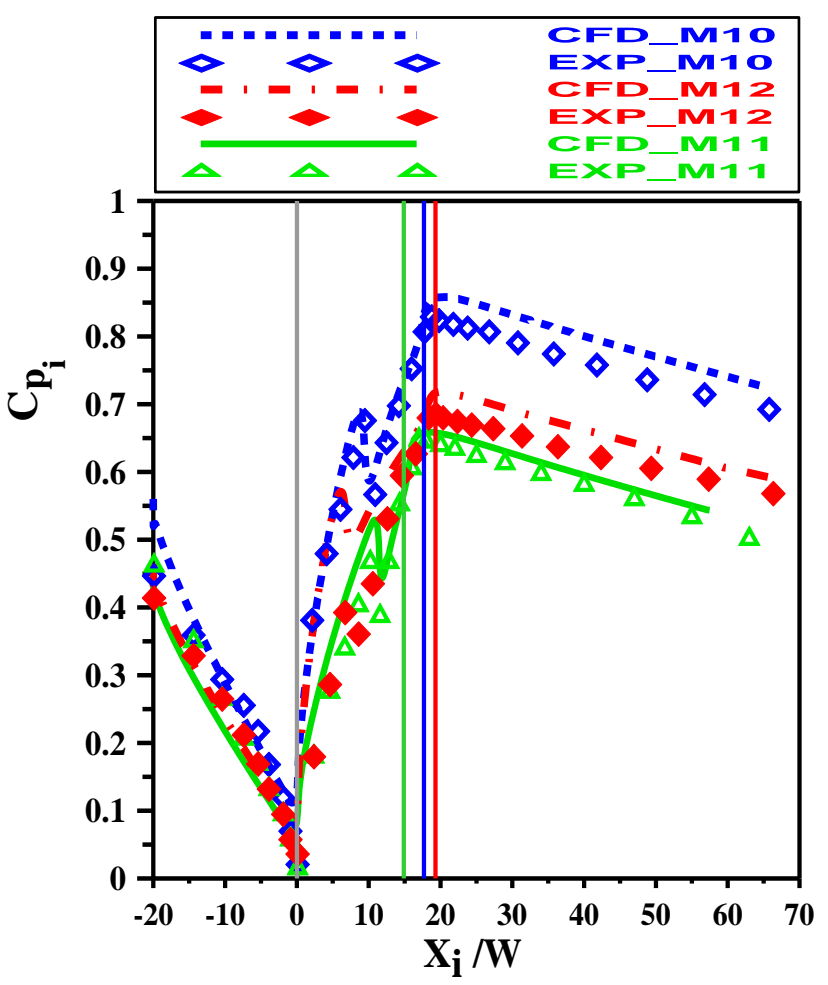

(b) inner-wall

Fig.8 Effect of S- diffuser flow path on pressure recovery coefficient at $\operatorname{Re}=34,000$

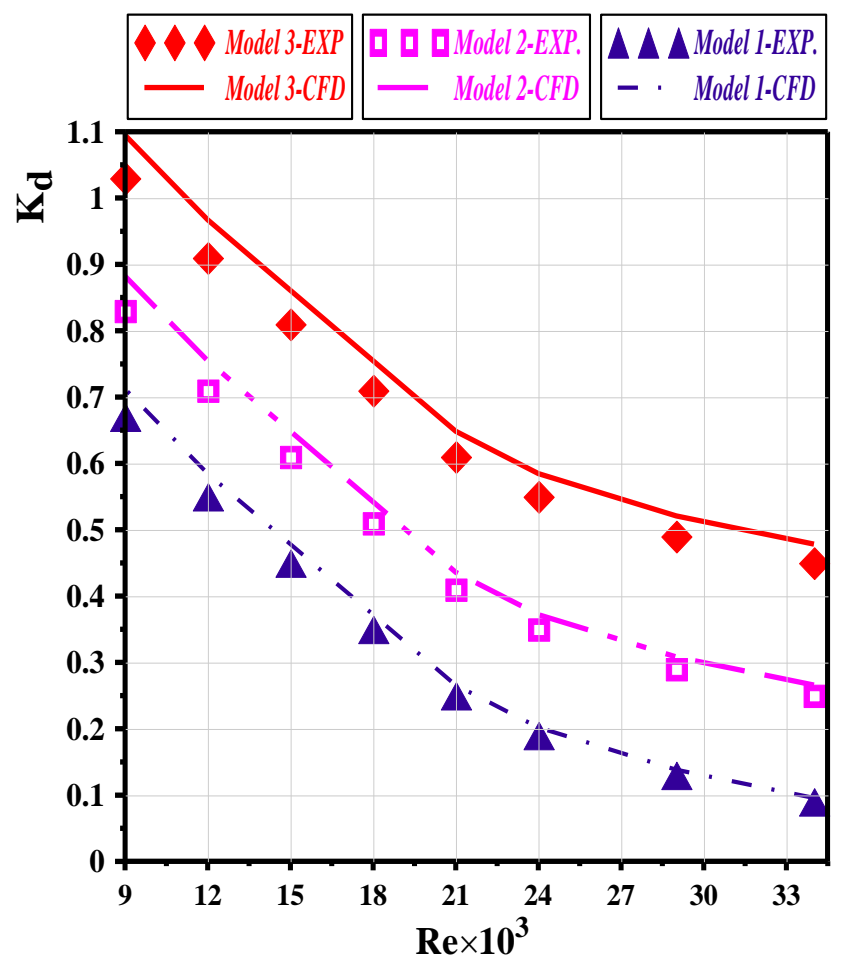

Fig.9 Effect of diffuser area ratio on the diffuser energy-loss coefficient

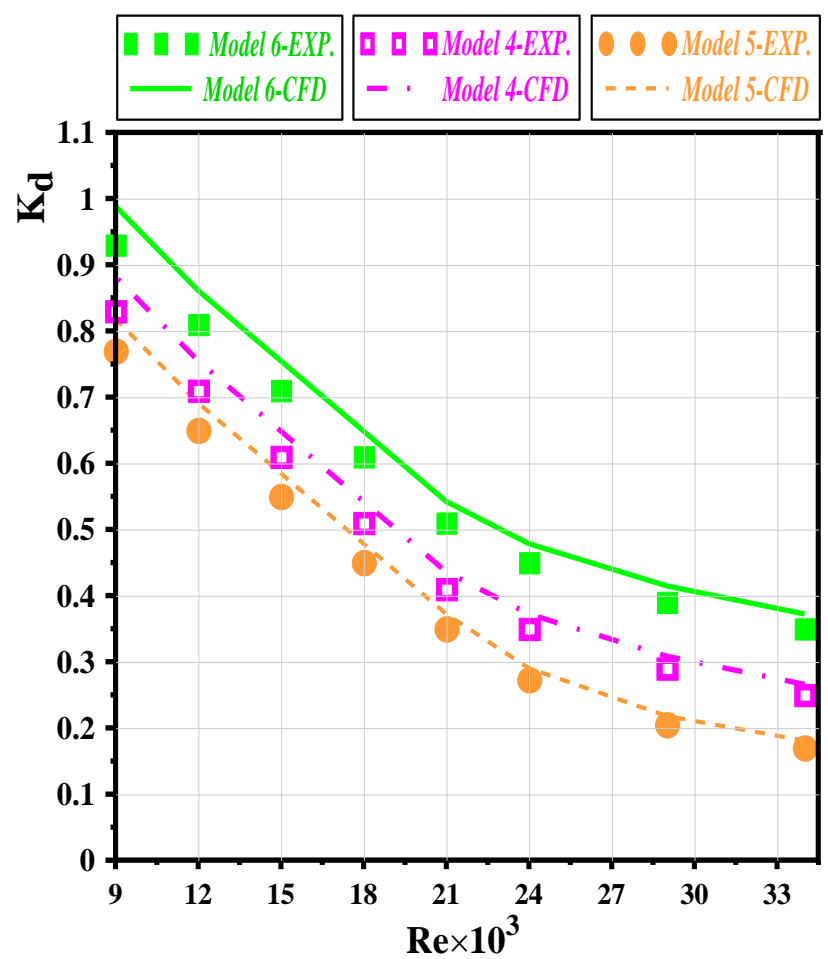

Fig.10 Effect of diffuser curvature ratio on the diffuser energy-loss coefficient 
"K. A. Ibrahim, W. A. El-Askary, E. Saker and Hamdy A. Omara, EXPERIMENTAL AND ..."

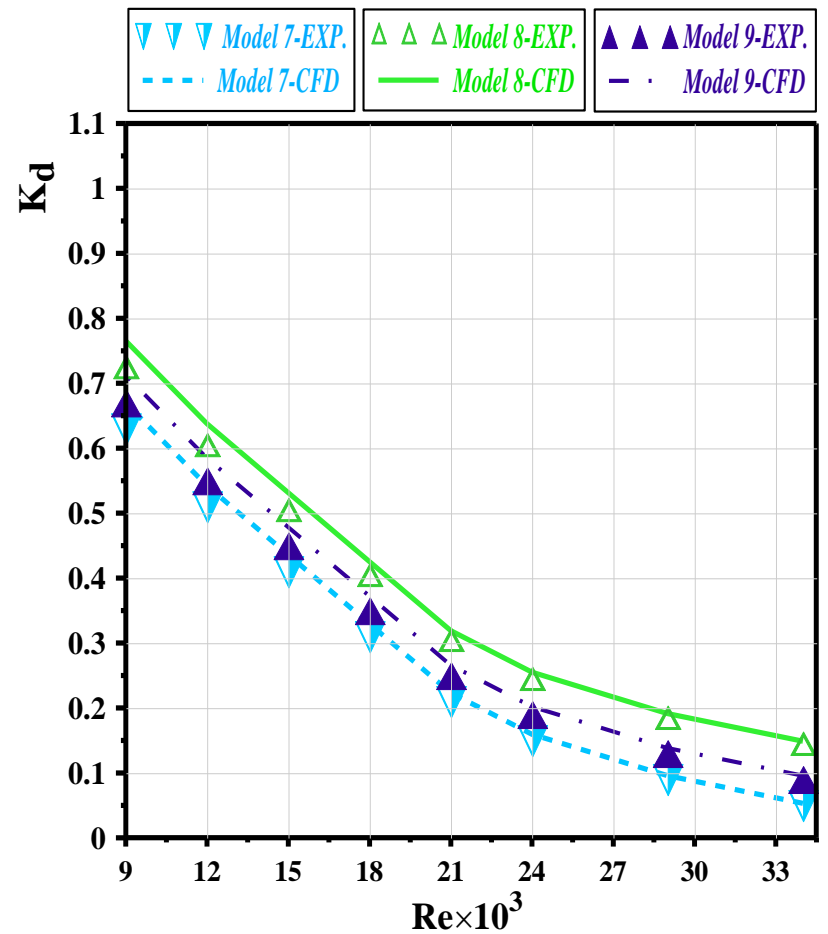

Fig. 11 Effect of diffuser turn angle on the diffuser energyloss coefficient

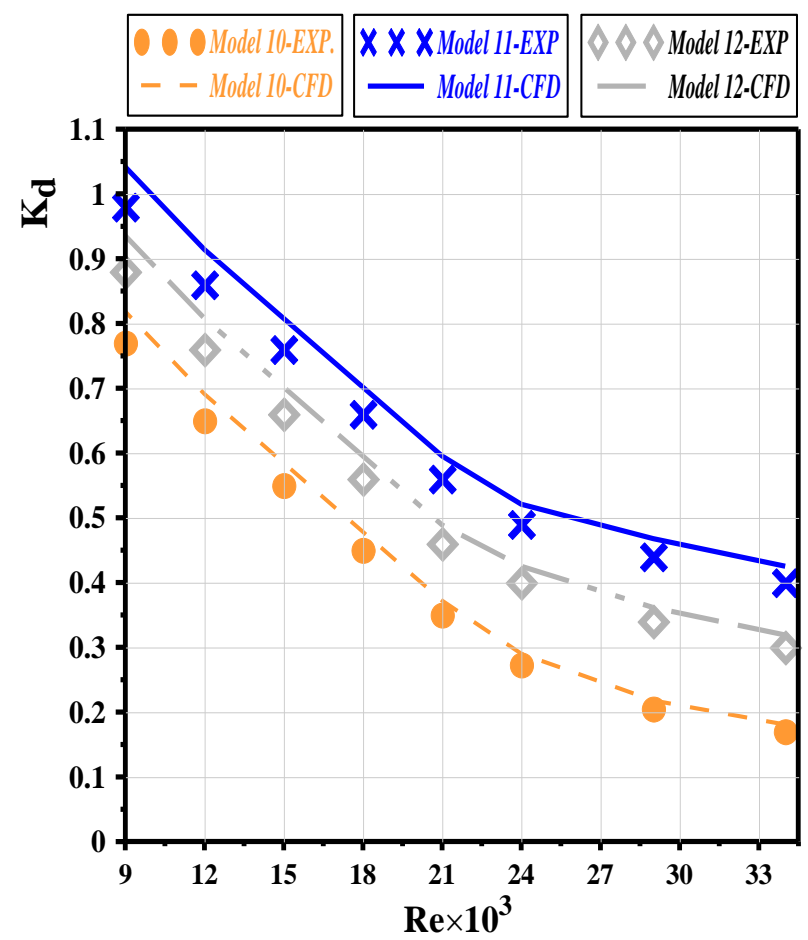

Fig. 12 Effect of diffuser flow path on the diffuser energyloss coefficient

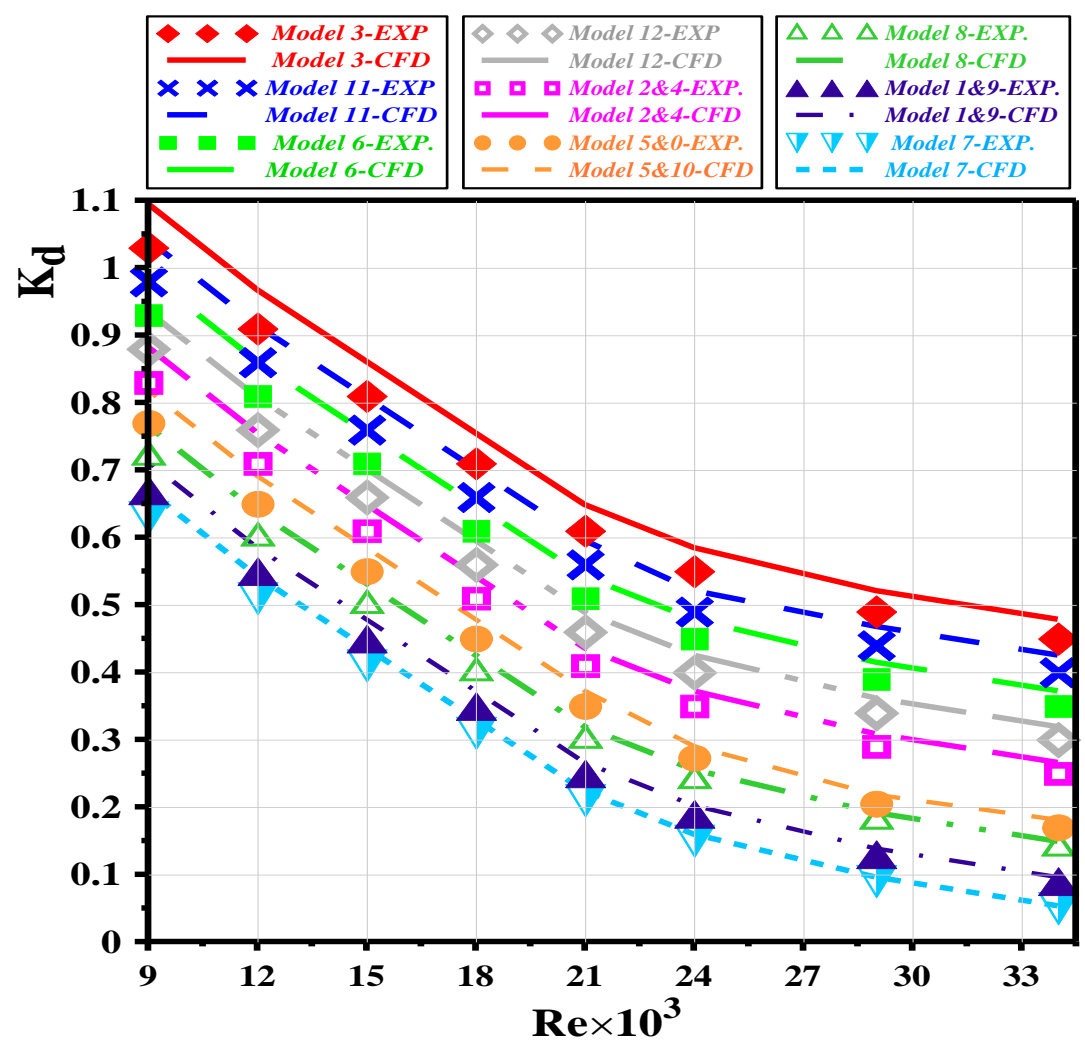

Fig.13 Effect of inflow Reynolds number on the energy-loss coefficient for all models 


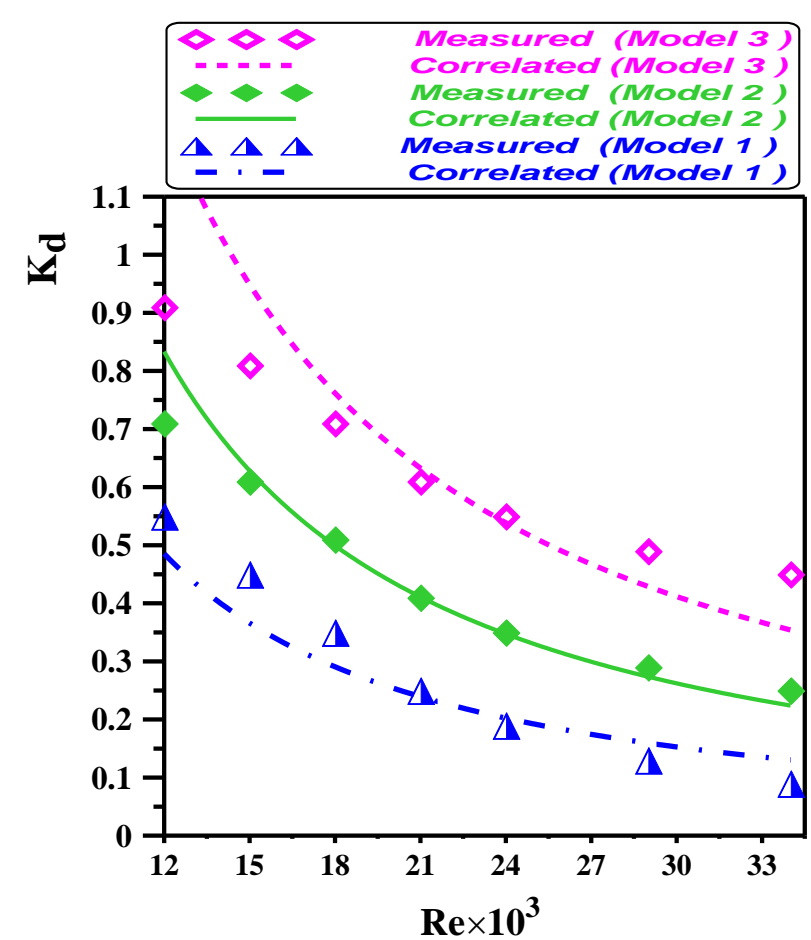

Fig. 14 Curve fitting for diffuser area ratio effect on the energy-loss coefficient

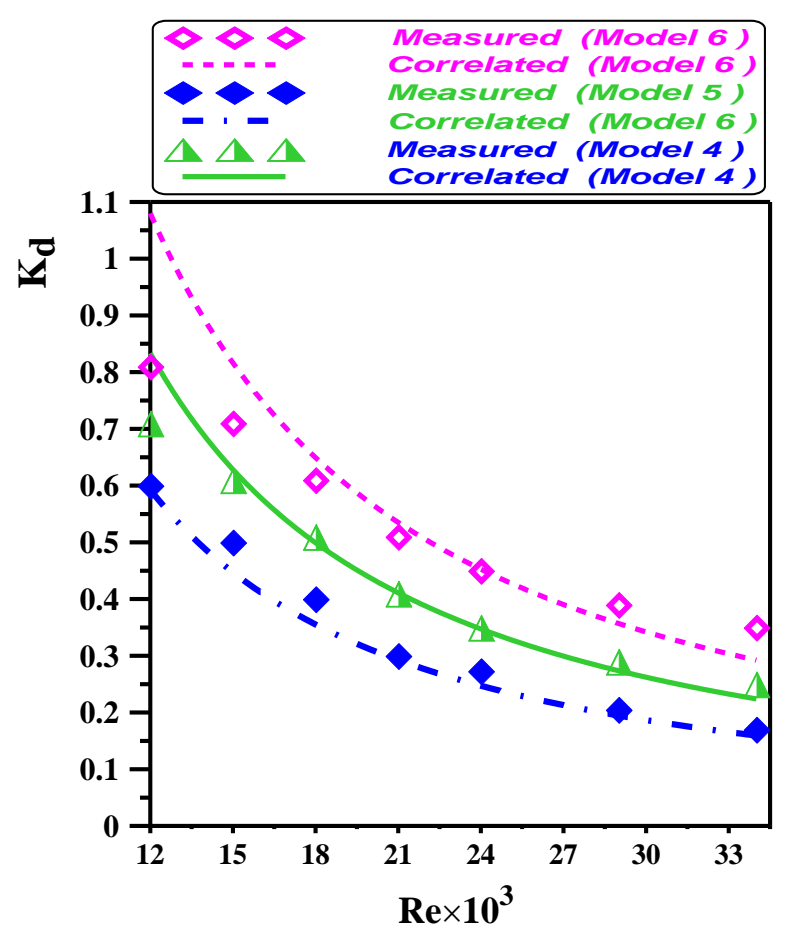

Fig. 15 Curve fitting for diffuser curvature ratio effect on the energy-loss coefficient

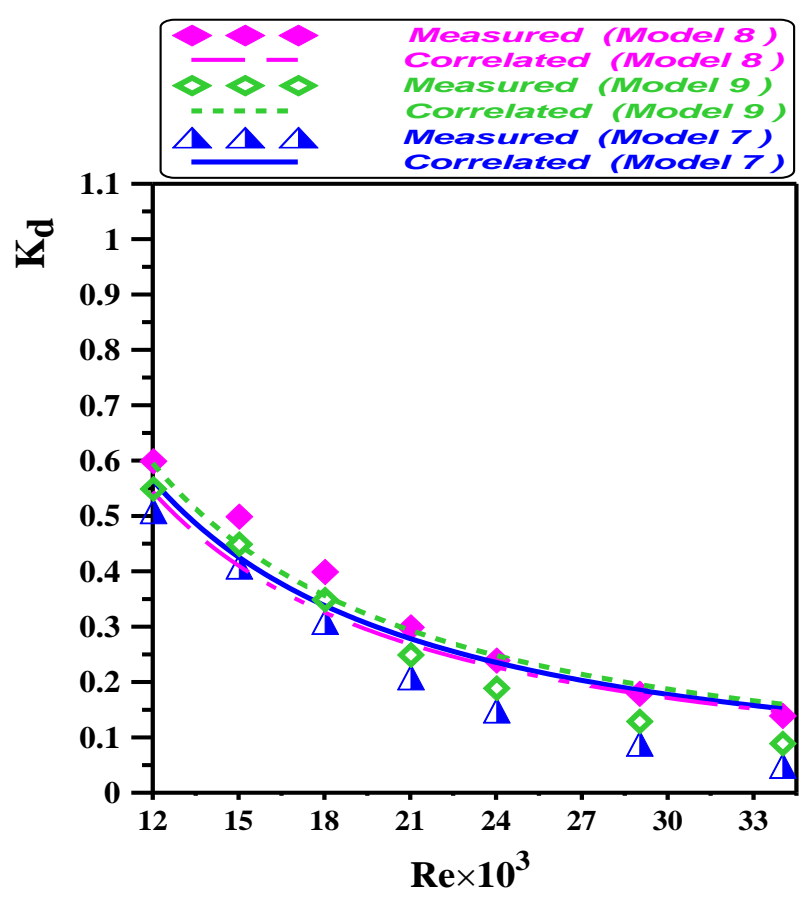

Fig. 16 Curve fitting for diffuser turn angle effect on the energy-loss coefficient

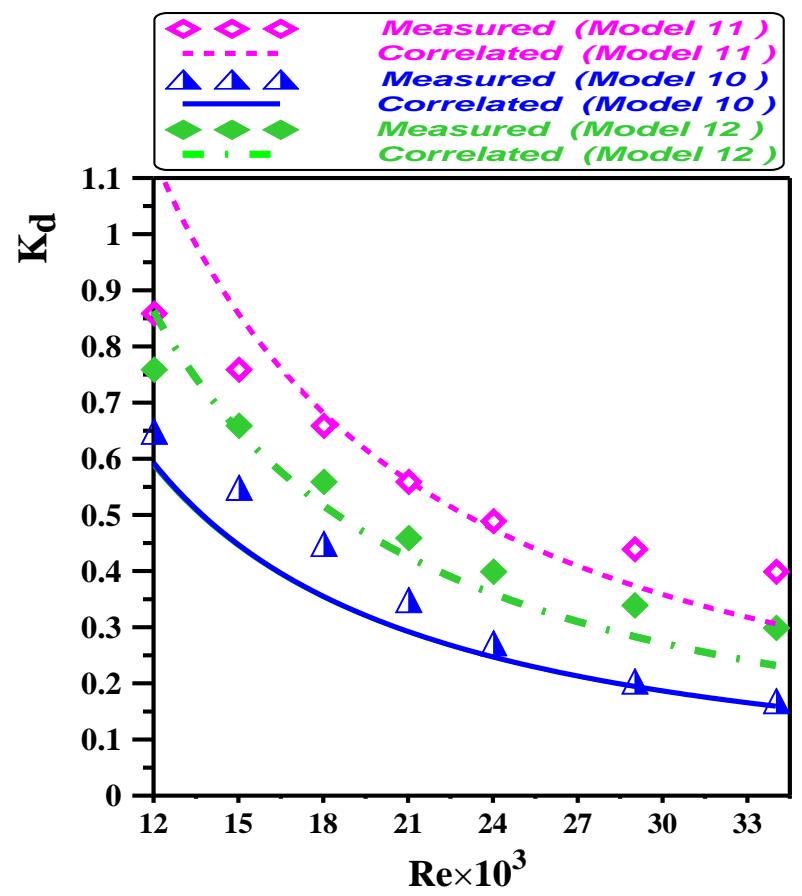

Fig. 17 Curve fitting for diffuser flow path effect on the energy-loss coefficient 
secondary flows (with small radius of curvature) superimposed on the mean flow, see Fig. 10. This behavior is attributed to the change of turbulence intensity which may be affected by the area ratio and the curvature ratio of the S- diffusers. The diffuser energy-loss coefficient is slowly affected by change of the symmetric turn angle because of the different three models turn angles are symmetric, see Fig. 11. These cause low water flow resistance through the Sdiffusers. At the same Reynolds number, the same curvature radius and the same sum of the two bends turn angles $\left(90^{\circ}\right)$ the energy-loss coefficient of the Sshaped diffuser increases with asymmetric turn angle and decreases with symmetric turn angle $\left(45^{\circ} / 45^{\circ}\right)$, see Fig. 12. This behavior tends to the created secondary flows because of the strong turn of Sshaped curved diffuser. This indicates the lower resistance to the water flow in the case of symmetric turn angle. The presence of asymmetric turn angle increases the drag of water to move in the $S$-shaped diffuser and this enhances the energy loss of the Sshaped diffuser.

\subsection{The Best Diffuser Model}

The experimental and numerical energy loss coefficients of all tested S-shaped diffuser models are presented in Fig. 13. The energy loss coefficient decreases with high Reynolds number because of the reduction of adverse pressure gradient generated in the S-shaped diffuser, see Fig. 14. The comparisons reveal that the flow in Sshaped diffuser model (3) exhibits greater values of the diffuser energy-loss coefficient than the other models, while model (7) exhibits the lowest value of the energyloss coefficient compared with the other tested models. Therefore, the best design modeler of the S-shaped diffusers is model (7) which has area ratio of 3 , curvature ratio of 7.5 , and symmetric center-line turn angle of $\left(60^{\circ} / 60^{\circ}\right)$.

\subsection{Loss Coefficient Correlation}

A general new correlation of the S-diffuser loss coefficient (not previously considered) for the present studied cases exploring the ranges of geometrical parameters and inflow Reynolds number range can be extracted from the experimental data.

Correlation equation can be extracted from the curve fitting and can be written as:

$$
K_{d}=\frac{7.15 \times 10^{5} \times \theta_{1}^{0.10} \times\left[\theta_{2} / \theta_{1}\right]^{0.90}}{\operatorname{Re}^{1.255} \times C R^{0.666} \times A R^{1.333}}
$$

The effects of S-diffuser geometrical parameters; area ratio, curvature ratio, turn angle, and flow path on the correlated diffuser energy-loss coefficient are shown in Figs. 15 to 17 , in which good comparisons between the developed correlation and the present results.

\section{CONCLUSIONS}

Based on the experimental and numerical results, and related discussions the following conclusions can be drawn:

1- $\quad$ For all tested models the static pressure recovery coefficient $\left(C_{p}\right)$ decreases through the upstream tangent and the downstream tangent by different values from an $\mathrm{S}$-shaped diffuser model to other. While, it increases through the S-diffuser by different values from a model to other.

2- The energy-loss coefficient of S-shaped diffusers is found to be inversely proportional to the generalized Reynolds number, Re.

3- For S-shaped diffusers as the area ratio (AR) increases from 1.5 to 3.0 , and the curvature ratio $\left(\mathrm{CR}=R_{c} / W\right)$ increases from 5 to 12.5 , the energy-loss coefficient decreases.

4- As the turn angle increases from $45^{\circ} / 45^{\circ}$ to $90^{\circ} / 90^{\circ}$, the energy-loss coefficient hardly increases since magnitudes of the counter rotating vortices being higher for the higher angle of turn.

5- As the flow path changes as $45^{\circ} / 45^{\circ}, 30^{\circ} / 60^{\circ}$, $60^{\circ} / 30^{\circ}$ the energy-loss coefficient strongly increases respectively.

6- The best design modeler of the S-diffusers is model (7) which has area ratio of 3 , curvature ratio of 7.5 , and symmetric center-line turn angle of $\left(60^{\circ} / 60^{\circ}\right)$ which exhibits the lowest value of the energy-loss coefficient compared with the other models.

7- Good correlations equation is obtained and valid all cases studied in this paper.

Table.1 the Geometrical parameters of S-shaped diffuser models with $\mathrm{B}=8, \mathrm{~W}=2$ and $\mathrm{A}_{\text {inlet }}=16$ (Dimensions in $\mathrm{cm}$ )

\begin{tabular}{|c|l|c|c|c|c|c|}
\hline $\begin{array}{l}\text { Diffuser } \\
\text { model }\end{array}$ & $\boldsymbol{\Theta 1} / \mathbf{O 2}$ & $\boldsymbol{R}_{\mathbf{c}}$ & $\boldsymbol{W}_{\text {exit }}$ & $\boldsymbol{A}_{\text {exit }}$ & $\boldsymbol{A R}$ & $\boldsymbol{C R}$ \\
\hline $1 \& 9$ & $45^{\circ} / 45^{\circ}$ & 15 & 6 & 48 & 3 & 7.5 \\
\hline $2 \& 4$ & $45^{\circ} / 45^{\circ}$ & 15 & 4 & 32 & 2 & 7.5 \\
\hline 3 & $45^{\circ} / 45^{\circ}$ & 15 & 3 & 24 & 1.5 & 7.5 \\
\hline $5 \& 10$ & $45^{\circ} / 45^{\circ}$ & 25 & 4 & 32 & 2 & 12.5 \\
\hline 6 & $45^{\circ} / 45^{\circ}$ & 10 & 4 & 32 & 2 & 5 \\
\hline 7 & $60^{\circ} / 60^{\circ}$ & 15 & 6 & 48 & 3 & 7.5 \\
\hline 8 & $90^{\circ} / 90^{\circ}$ & 15 & 6 & 48 & 3 & 7.5 \\
\hline 11 & $60^{\circ} / 30^{\circ}$ & 25 & 4 & 32 & 2 & 12.5 \\
\hline 12 & $30^{\circ} / 60^{\circ}$ & 25 & 4 & 32 & 2 & 12.5 \\
\hline
\end{tabular}


Table.2 Uncertainty of the energy-loss coefficients of the S-shaped diffuser models

\begin{tabular}{|c|c|c|}
\hline $\begin{array}{l}\text { Diffuser } \\
\text { model }\end{array}$ & Range of $K_{d}$ & $\begin{array}{l}\text { percentage } \\
\text { uncertainty } \pm U_{k_{d}} \%\end{array}$ \\
\hline $1 \& 9$ & $0.18 \leq K_{d} \leq 0.80$ & $3.6 \leq \pm U_{k_{d}} \% \leq 4.0$ \\
\hline $2 \& 4$ & $0.26 \leq K_{d} \leq 0.86$ & $2.9 \leq \pm U_{k_{d}} \% \leq 3.2$ \\
\hline 3 & $0.42 \leq K_{d} \leq 0.98$ & $3.3 \leq \pm U_{k_{d}} \% \leq 3.9$ \\
\hline $5 \& 10$ & $0.05 \leq K_{d} \leq 0.65$ & $2.6 \leq \pm U_{k_{d}} \% \leq 2.9$ \\
\hline 6 & $0.48 \leq K_{d} \leq 1.1$ & $2.8 \leq \pm U_{k_{d}} \% \leq 3.2$ \\
\hline 7 & $0.09 \leq K_{d} \leq 0.69$ & $2.2 \leq \pm U_{k_{d}} \% \leq 2.7$ \\
\hline 8 & $0.14 \leq K_{d} \leq 0.74$ & $3.0 \leq \pm U_{k_{d}} \% \leq 3.5$ \\
\hline 11 & $0.36 \leq K_{d} \leq 0.96$ & $2.7 \leq \pm U_{k_{d}} \% \leq 3$ \\
\hline 12 & $0.31 \leq K_{d} \leq 0.91$ & $3.1 \leq \pm U_{k_{d}} \% \leq 3.6$ \\
\hline
\end{tabular}

\section{REFERENCES}

1- Gopaliya, M. K., Kumar, M., Kumar, S., and Gopaliya, S. M., "Analysis of performance characteristics of S-shaped diffuser with Offset", Aerospace Science and Technology, Vol.11, PP. 130-135, (2007).

2- Gopaliya, M. K., Goel, P. and Prashar, S., "CFD Analysis of Performance Characteristics of S-Shaped Diffusers with Combined Horizontal and Vertical Offsets", Computers \& Fluids journal, Vol. 40, PP. 280-290, (2011).

3- Glyn, N., "Flows Through S-Shaped Annular, Inter-Turbine Diffusers", A Thesis submitted for the degree of Doctor of Philosophy, PP. 1-228, (1997).

4- Reneau, L. R., Johnston, J. P. and Kline, S. J., "Performance and Design of Straight, TwoDimensional Diffusers", Journal of Basic Engineering, Transactions of the ASME, Vol. 89, PP. 141-150, (March 1967).

5- Bansod, P., and Bradshaw, P., "The Flow in SShaped Ducts", Aeronautical Quarterly no. 23 (2), PP. 131-140, (1972).

6- McMillan, O. J., "Mean-Flow Measurements of the Flow Field Diffusing Bend", NASA Contractor Report 3634, (1982).
7- Taylor, A. M. K. P., Whitelaw, J. H. and Yianneskis, M., "Developing Flow in S-Shaped Ducts of Square Cross-Section", National Aeronautics and Space Administration, NASA Contractor Report 3550, Scientific and Technical Information Office, PP. 1-50, (1982).

8- Taylor, A. M. K. P., Whitelaw, J. H. and Yianneskis, M., "Developing Flow in S-Shaped Ducts of Circular Cross-Section", National Aeronautics and Space Administration, NASA Contractor Report 3759, Scientific and Technical Information Office, PP. 1-56, (1984).

9- Sullerey, R. K., "Performance Comparison of Straight and Curved Diffusers", Defence Science Journal Vol. 33, No 3, July 1983, PP. 195-203, (1983).

10- Whitelaw, J. H. and Yu, S. C. M., "Flow Characteristics in an S-Shaped Diffusing Duct with Asymmetric Inlet Conditions", 11 th Australasian Fluid Mechanics Conference, Univerisity Tasmania, Hobart, Australia, PP. 139-142, (14-18 December 1992).

11- Whitelaw, J. H. and Yu, S. C. M., " Velocity Measurements in an S-Shaped Diffusing Duct", Experiments in Fluids Vol.15 (4), PP. 364-367, (1993a).

12- Whitelaw, J. H. and Yu, S. C. M., "Turbulent Flow Characteristics in an S-Shaped Diffusing Duct", Flow Measurement and Instrumentation, Vol. 4 (3), PP. 171-179, (1993b).

13- Britchford, K.M., Manners, A.P., McGuirk, J.J. and Stevens, S.J., "Measurements and Prediction of Flow in Annular S-shaped Ducts", Proceedings of the Second International Symposium on Engineering Turbulence Modelling and Measurements, Florence, Italy, PP. 785-794, (1993).

14- Britchford, K.M. Carrotte, J.F., Stevens, S.J. and McGuirk, J.J., "The Development of the Mean Flow and Turbulent Structure in an Annular S-shaped Duct", 94-GT-457, (1994).

15- Glyn, N., "Flows Through S-Shaped Annular, InterTurbine Diffusers", A Thesis submitted for the degree of Doctor of Philosophy, PP. 1-228, (1997).

16- Anderson, B. H., Reddy, D. R. and Kapoor, K., "Study on computing separating flows within a diffusion inlet S-duct", Journal of Propulsion and Power no. 10 (5), PP. 661-667, (1999).

17- Bruns, J. M., Fernholz, H. H., and Monkewitz, P. A., "An Experimental Investigation of a ThreeDimensional Turbulent Boundary Layer in an ' $\mathrm{S}$ 'Shaped Duct", Journal of Fluid Mechanics Vol. 393 (1), PP. 175-213, (1999). 
18- Gupta, V., Devpura, R., Singh, S. N. and Seshadri, V., "Effect of Aspect Ratio and Curvature on Characteristics of S-Shaped Diffusers", Indian Journal of Engineering \& Materials Sciences, Vol. 8, PP. 141-148, (June 2001).

19- Garbaruk, A. V., Strelets, M. K. and Shur, M. L., "Analysis of three-dimensional turbulent flow in an S-shaped rectangular channel", Vol.41(1) , PP. 49-56, (2003).

20- Sinha, P. K., Seshadri, V., Chandel, S. and Gaikwad, M., "Analysis of the Improvement in Performance Characteristics of S-Shaped Rectangular Diffuser by Momentum Injection Using Computional Fluid Dynamics", Engineering Applications of Computional Fluid Mechanics, Vol. 3, No. 1, PP. 109-122, (2009).

21- El-Askary, W.A. and Nasr, M., "Performance of a Bend-Diffuser System: Experimental and Numerical Studies", Journal of Computers and Fluids, Vol. 38(1), PP. 160-170, (2009).

22- Sinha, P. K. and Majumdar, B., "Numerical Studies of Flow Through Annular Curved Diffuser", International Journal of Advances in Engineering\& Technology, Vol. 1, Issue 3, PP. 98-104, (2011).

23- Das, N. K., Raman, A. K., Mullick, A. N., Halder, B., Ray, P. and Majumdar, B., "Numerical Validation of Flow Through an S-Shaped Diffuser", Singapore, International Conference on Fluid Dynamics and Thermodynamics Technologies, Vol. 33, (2012).
24- Abdellatif, O. E., Abd Rabbo, M. A. and Shahin, I. M., "Computational Study Of Center Line Turning Angle Effect On The Turbulent Flow Through A Diffusing S-Duct Using Large-Eddy Simulation", Engineering Research Journal, Shoubra Faculty of Engineering, Benha University, Cairo, PP. 1-20, (2012)

25- Biswas, A. K., Prasanta, K., Sinha, P. K., Mullick, A. N. and Majumdar, B., "Flow Investigation in a Constant Area Curved Duct", International Journal of Engineering Research and Applications (IJERA), Vol. 2, Issue6, PP. 1232-1236, (2012).

26- El-Askary, W. A., Ibrahim, K. A., Wahba, E. and Omara H. A., "Experimental Flow Investigation of Curved Diffuser", International Journal of Fluid Mechanics Research, , Vol. 40, No. 3, PP. 204-226, (2013).

27- Pau, A. R., Ranjan, P., Patel, V. K., and Jain, A., "Comparative Studies On Flow Control In Rectangular S-Duct Diffuser Using SubmergedVortex Generators", Aerospace Science and Technology, Vol. 28, PP. 332-343, (2013).

28- Gopaliya, M. K., Jain, P., Kumar, S., Yadav, V. and Singh, S., "Performance Improvementof Sshaped Diffuser Using Momentum Imparting Technique", Journal of Mechanical and Civil Engineering, Vol. 11, Issue 3, PP. 23-31, (2014). 